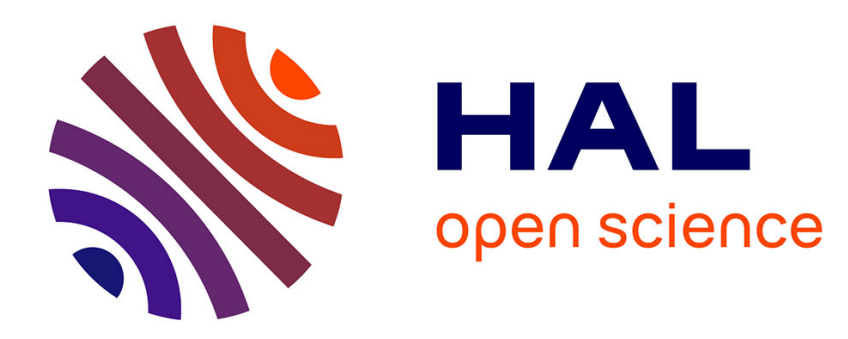

\title{
Messianisme royal de la Couronne d'Aragon
}

Martin Aurell

\section{To cite this version:}

Martin Aurell. Messianisme royal de la Couronne d'Aragon. Annales. Histoire, Sciences sociales, 1997, 52e année (1), pp.119-155. 10.3406/ahess.1997.279555 . halshs-01306151

\section{HAL Id: halshs-01306151 https://shs.hal.science/halshs-01306151}

Submitted on 22 Apr 2016

HAL is a multi-disciplinary open access archive for the deposit and dissemination of scientific research documents, whether they are published or not. The documents may come from teaching and research institutions in France or abroad, or from public or private research centers.
L'archive ouverte pluridisciplinaire HAL, est destinée au dépôt et à la diffusion de documents scientifiques de niveau recherche, publiés ou non, émanant des établissements d'enseignement et de recherche français ou étrangers, des laboratoires publics ou privés. 


\title{
Messianisme royal de la Couronne d'Aragon
}

\section{Martin Aurell}

\author{
Abstract \\ Royal Messianism of the Crown of Aragon (14th-15th centuries). M. Aurell.
}

During the end of the Middle Ages, while modern State was growing, kings spread political propaganda to support the increasing of their power and their wars against other countries. For Catalan-Aragonese monarchy, heiress of Frederik II, prophecy was a good mean of fighting against papacy and Angevins for the supremacy in Southern Italy. The religious dissidence of the kings of Aragon induced them to receive many spiritual Franciscans persecuted under John XXII and to create some insular utopias based on poverty in their own kingdoms. These friars were fond of joachite theories announcing that the end of the world was soon arriving. They believed on an emperor who would found universal monarchy with a peaceful millenium, after having annihilated decadent clerics, beaten Muslims and conquered Jerusalem. This kind of Antichrist or exterminator angel was personified in the king of Aragon, who took paradoxically advantage of the apocalyptic metaphors of the winged dragon, the bat, the eagle, the fire or the smoke. These negative images were used in Catalonia to affirm a primitive national identity, fighting behind the royal dynasty.

\section{Citer ce document / Cite this document :}

Aurell Martin. Messianisme royal de la Couronne d'Aragon. In: Annales. Histoire, Sciences Sociales. 52 année, N. 1, 1997. pp. 119-155;

doi : 10.3406/ahess.1997.279555

http://www.persee.fr/doc/ahess_0395-2649_1997_num_52_1_279555

Document généré le 14/03/2016 


\section{MESSIANISME ROYAL DE LA COURONNE D'ARAGON $\left(14^{\mathrm{e}}-15^{\mathrm{e}}\right.$ SIÈCLES)}

Martin AurelL

Depuis une dizaine d'années, l'historiographie du politique retrouve un second souffle. Sous son impulsion, le thème de la genèse médiévale de l'État moderne mobilise les chercheurs'. Une vaste enquête collective approfondit les principaux éléments du nouveau système de gouvernement, dont sont redevables, encore de nos jours, les sociétés occidentales : renforcement des institutions monarchiques, fiscalité accrue, apparition des assemblées représentatives, triomphe de la royauté sur le Saint-Siège, découverte de l'aristotélisme politique... Ce profond bouleversement, qui intervient autour des années 1280-1360, ne va pas sans heurts : la guerre, monopole royal, justifiant des prélèvements fiscaux obligatoires, contribuant à l'éclosion du patriotisme, est la toile de fond sur la scène de la naissance des structures étatiques, où épidémies et disettes ne sont pas de moindres comparses ${ }^{2}$. Les cavaliers de l'Apocalypse - conflits, peste et famine se jettent, à bride abattue, sur l'Occident.

Ces malheurs des temps exacerbent le penchant eschatologique de populations frappées par l'expérience quotidienne et obsédante de la mort. Parmi elles, la croyance en l'imminence de la parousie se répand largement. A l'orée du $14^{\mathrm{e}}$ siècle, le prophétisme, naguère illumination divine réservée à l'exégèse des Écritures, à la réflexion théologique et à une prédication

* Cet article doit beaucoup aux travaux de l'URA 1011 du CNRS ( «L'institution ecclésiale à la fin du Moyen Age »), dirigée par André Vauchez, et à son équipe du Livre révélateur (1356) de Jean de Roquetaillade. Que tous ses membres en soient sincèrement remerciés, tout comme les participants au séminaire "Les pouvoirs (XIII'-XV" siècle) », sous la direction de Philippe Contamine et de Françoise Autrand, où une version provisoire de cette étude a été présentée en janvier 1994. Enfin, l'aide du groupe d'historiens de la péninsule Ibérique, animé par Bernard Vincent et par Adeline Rucquoi à l'EHESS nous a été précieuse.

1. Genèse de l'État moderne. Bilans et perspectives, J.-P. GENET éd., Paris, 1990.

2. P. Contamine, Guerre, État et société à la fin du Moyen Age. Paris, 1972 ; C. Beaune, Naissance de la nation France, Paris, 1985. 


\section{RITES, MÉMOIRE ET PROPHÉTIES}

axée sur la considération de l'au-delà ${ }^{3}$, prend un nouveau visage : il fixe, à partir d'une interprétation des prodromes de la fin qui approche, la date de la destruction prochaine de l'univers.

Il multiplie, de même, ses intentions politiques. Visions et révélations s'affirment avec force en marge des institutions et des corps établis. Elles appartiennent, certes, à la catégorie des « pouvoirs informels » à forte charge subversive $^{4}$ : les mouvements dissidents et hétérodoxes en font un large usage à l'encontre de la royauté et de la hiérarchie ecclésiastiques. Mais, détournées de leur fonction première, ces paroles inspirées peuvent, paradoxalement, contribuer au triomphe de quelques lignées royales dans l'esprit de leurs sujets et à leur victoire sur les États ennemis. Certains princes, entourés de prophètes, créent et diffusent une propagande apocalyptique encourageant leur construction étatique.

Au cours des $14^{\mathrm{e}}$ et $15^{\mathrm{e}}$ siècles, les rois d'Aragon font l'objet de multiples prophéties qui leur attribuent une fonction messianique. En 1282, la maison de Barcelone, prenant possession de la Sicile, s'approprie des oracles, venus d'Orient et réélaborés par les disciples de Joachim de Flore (1130-1202), dont le trithéisme historique exalte la figure de l'Empereur des derniers temps. Les Trastamare castillans, à la tête de la confédération catalanoaragonaise dès 1412 , ne récusent nullement cet héritage, apte à renforcer une domination contestée en Catalogne. Engagés dans une ambitieuse aventure impérialiste, les rendant maîtres des grandes îles de la Méditerranée occidentale et d'une partie des Balkans, les rois d'Aragon croient à leur mission providentielle. Ennemis de la papauté dans leur expansion italienne, ils tirent profit du caractère subversif du prophétisme joachimite, récupéré au service d'une dissidence d'État. Des vaticinations venues du ciel justifient leur politique extérieure, que combat le Saint-Siège, protecteur de la maison de France et des Angevins de Naples.

Elles servent ouvertement l'action de la monarchie à l'intérieur de la Couronne d'Aragon. Comme partout en Occident, une crise sans précédent renverse, à l'époque, la position royale : d'arbitre et de garant d'un droit préexistant, le prince se transforme en législateur suprême, tandis que l'utilité publique se confond avec ses propres intérêts ${ }^{6}$. Le prophétisme l'aide dans sa tentative de brimer l'autonomie de ses principautés et d'écraser les libertés des corps intermédiaires : ses territoires ont été, jusqu'alors, régis par le pactisme, un système de gouvernement ancien, où les nombreux privilèges des différentes communautés regroupant les sujets de la Couronne privent le roi du plein exercice d'un pouvoir absolu. L'appui de ces vaticinations au nouveau programme de la monarchie est essentiel pour gou-

3. J.-P. TORRELl, Recherches sur la théorie de la prophétie au Moyen Age, XII'-XIV' siècles, Fribourg, 1992.

4. C. Beaune, A. Vauchiz, "Recherches sur le prophétisme en Occident (XII ${ }^{\mathrm{e}}-\mathrm{XV}^{\mathrm{e}}$ siècle), dans Genèse de l'État..., op. cit., pp. 201-206.

5. Christianisme médiéval. Mouvements dissidents et novateurs, A. VAuJHEZ, A. BRENON éds, numéro spécial de la revue Heresis, 1990.

6. G. GiORDANENGO, «Du droit civil au pouvoir royal », Public, privé : espaces et gestions, Lyon, 1987, pp. 9-25. 
verner, de façon uniforme, la confédération catalano-aragonaise, dépourvue de toute tradition politique unitaire ${ }^{7}$. Dans le combat qui les oppose aussi bien aux habitants de leurs propres États qu'aux dynasties voisines, les Barcelonais et les Trastamare ne sauraient se passer de ces oracles rehaussant leur prestige.

Une cinquantaine de prophéties les mentionnant sont arrivées jusqu'à nous $^{8}$. Quelques-uns de ces textes ont la dynastie régnante pour objet exclusif de leurs développements : ils appartiennent à cette catégorie de vaticinations exploitées, de façon opportuniste, par factions et partis dans le seul but d'obtenir un succès politique. Mais des allusions au messianisme royal sont, plus souvent, insérées dans de longs traités eschatologiques abordant l'exégèse biblique, prônant la réforme morale et décrivant le second avènement du Christ : royauté et spiritualité se confondent dans ces documents qui traduisent la fusion entre le politique et le religieux dans la mentalité de l'homme médiéval. Rédigés en latin ou en catalan entre la fin du $13^{\mathrm{e}}$ et le début du $16^{\mathrm{e}}$ siècle, ils ne représentent que la partie immergée de l'iceberg d'un ensemble d'oracles circulant de façon orale ou dans des feuilles volantes qui n'ont guère résisté au passage du temps. Le caractère répétitif de cette littérature, trop souvent commentaire suranné des paroles mystérieusement données à des prophètes d'antan, réduit cependant la portée de ces pertes documentaires. L'échantillon dont nous disposons permet aisément de pénétrer un imaginaire messianique, ses figures, ses racines et son fonctionnement.

\section{Un milieu favorable : rois, prophètes et franciscains}

Les rois d'Aragon manifestent un intérêt ouvert pour les oracles, surtout quand ils concernent l'avenir de leurs propres principautés. Ils accueillent de nombreux prophètes et astrologues. Ils prêtent une oreille attentive aux plus exaltés des franciscains spirituels, aussi bien catalans qu'italiens, qu'ils reçoivent volontiers dans leurs palais. Loin d'être des marginaux ou des "fanatiques de l'Apocalypse », voués aux marges d'une hétérodoxie incertaine, ces futurologues avant la lettre ont leurs entrées à la cour de Barcelone. En ville, ils sont adulés par la classe marchande montante. En parfaite osmose avec la société de leur temps, soucieuse de lire dans les signes des temps les prodromes de la fin du monde, ces personnages ont laissé maintes traces dans les archives. La correspondance du roi, les mandements de sa chancellerie et les actes notariés, tout comme les registres de l'inquisition sous le pontificat de Jean XXII (1316-1334), nous introduisent dans leur milieu, qui est, trop souvent, celui de la cour royale.

7. R. d'Abadal, Pere el ceremoniós $i$ els inicis de la decadència política de Catalunya, Barcelone, 1972, p. 61.

8. Elles ont été inventoriées par P. Bohigas, "Profecies catalanes dels segles XIV i XV. Assaig bibliogràfic ", Butlletí de la Biblioteca de Catalunya, 1920-1922, pp. 24-49, et "Profecies de Merlí. Altres profecies contingudes en manuscrits catalans », ibid., 1928-1932, pp. 253279. Pour le $14^{\mathrm{c}}$ siècle, de nombreuses transcriptions et analyses dans J. M. Pou, Visionarios, beguinos y fraticelos catalanes, Vic, 1930. 


\section{RITES, MÉMOIRE ET PROPHÉTIES}

\section{L'exploitation de la prophétie et de l'astrologie}

Le 30 novembre 1361, le roi Pierre IV (1336-1387) dictait une lettre à l'adresse de l'amiral Francesc de Perellós, l'un de ses sujets demeurant à Paris. Il lui demandait d'acheter, dans cette ville, un manuscrit des Chroniques des rois de France, dont il avait égaré l'exemplaire. Il lui rappelait le début de cet ouvrage rapportant le triple rêve de l'épouse de Mérovée, qui avait eu successivement la vision des lions, des ours et des chiens. Pierre IV interprétait l'image de la qualité décroissante de ces trois animaux dans le sens d'une décadence progressive de la maison de France, aboutissant à l'échec de la croisade qu'en 1285 Philippe III avait conduite contre la Catalogne. Cette anecdote ne témoigne pas seulement du goût personnel que le roi d'Aragon éprouvait pour les oracles; elle traduit encore la manipulation partisane à laquelle il se livrait à partir d'un matériau prophétique d'une grande plasticité. A la même époque, au contraire, de l'autre côté des Pyrénées, le rêve de la nuit des noces de Basine, extrait de la chronique de Frédégaire, servait à justifier la continuité du sang des rois de France, unique et perpétuel, dans ses trois générations des lions mérovingiens, des ours carolingiens et des chiens capétiens'. La même prophétie, interprétée dans un sens radicalement opposé, devenait une arme redoutable dans le combat que se livraient les deux maisons.

Les rois d'Aragon tentaient de contrôler la production prophétique, élément essentiel dans leur propagande de guerre. En 1391, Jean Ir (13871395) morigénait le franciscain Francesc Eiximenis (1330-1409) qui, se fondant sur les oracles de l'Auvergnat Jean de Roquetaillade, avait prédit, au chapitre 466 de son Chrestià, que la monarchie d'Aragon ne dépasserait pas l'année 1400, époque à laquelle seule la maison de France subsisterait au monde. Le roi venait de lire la lettre, conservée dans ses archives, que Roquetaillade avait adressée à son père Pierre IV à ce sujet; il avait, en outre, consulté Cresques, un astrologue juif de la cour : il ressortait de ces recherches la fausseté des prédictions de Jean de Roquetaillade, que Jean $\mathrm{I}^{\mathrm{r}}$, par l'entremise de son maître rationnel, enjoignait à Eiximenis d'abandonner. Celui-ci s'exécuta aussitôt : le chapitre 473 de son ouvrage promettait la monarchie universelle du roi d'Aragon ${ }^{10}$. Bel exemple de mainmise et de la manipulation des prophéties politiques par la royauté !

Les registres de la chancellerie royale conservent d'autres lettres reflétant l'intérêt de Jean $I^{\text {er }}$ pour découvrir l'avenir : ses consultations aux prophètes de ses principautés sont nombreuses ${ }^{11}$. Les manuscrits contenant des oracles $\mathrm{s}^{\prime}$ entassent dans la bibliothèque royale ${ }^{12}$. A la fin du $14^{\mathrm{c}}$ siècle, les difficultés

9. J. CoRoleu, Documents historichs catalans del sigle XIV, Barcelone, 1889, pp. 52-53; C. BeAune, Le miroir du pouvoir, Paris, 1989, p. 144.

10. A. RuBıó, Documents per l'història de la cultura catalana mig-eval, Barcelone, 1908 et 1921 , t. I, pp. 372-373.

11. Ibid., t. I, pp. $377-378$ et t. II, p. 327.

12. J. MASSó, «Inventari dels bens mobles del rey Martí d'Aragó », Revue hispanique, 1905, pp. 413-590, $\mathrm{n}^{\circ} 101,120,246$, et T. de MARINIS, La biblioteca napoletana de $i$ re de Aragona, Milan, 1947 et 1969, t. II, p. 189. 
que les rois d'Aragon rencontrent pour maintenir leur domination sur la Sardaigne et sur la Sicile accroissent l'activité des prophètes catalans. Elles mettent souvent à contribution les astrologues, au cours d'une période où l'étude du cours des astres accorde un label scientifique aux plus osées des prédictions ${ }^{13}$. Nos monarques s'entourent d'astrologues, manient l'astrolabe et dépouillent les tables astronomiques ${ }^{14}$. A la cour d'Aragon, les visions sont soumises à l'analyse de l'astrologie, art des correspondances terrestres et célestes, donnant un rassurant aval de nature scientifique à des prophéties à l'authenticité incertaine.

L'image de la royauté apparaît alors inextricablement mêlée à l'astronomie. Lo somni (1399), cuvre maîtresse de Bernet Metge, secrétaire et homme de confiance de Jean $\mathrm{I}^{\mathrm{er}}$, traduit cette croyance $:$ le roi décédé rend visite à son auteur afin de lui communiquer qu'il peine dans le purgatoire pour son amour démesuré envers la chasse, la musique et l'astrologie ; le flûtiste Orphée et le devin Tirésias l'accompagnent dans l'au-delà pour lui rappeler ses fautes passées ${ }^{15}$. Une prophétie du début du $15^{\mathrm{e}}$ siècle rapporte, de façon anachronique, un dialogue entre Arnaud de Villeneuve et Pierre IV, dont les dons prophétiques lui valent le qualificatif de «roi astronome maxime ", rex maximus stronomus ${ }^{16}$. Astrologue, auréolé du savoir ésotérique réservé à un groupe restreint d'initiés, le roi prévoit l'avenir avec précision, prenant toujours les décisions qui s'imposent au triomphe de sa politique. Il peut ainsi se passer de l'avis des conseils institués et des assemblées représentatives.

A partir de 1412, l'avènement des Trastamare, en la personne de Ferdinand $\mathrm{I}^{\mathrm{er}} \mathrm{et}$ de ses descendants, ne modifie en rien l'attitude de la royauté à l'égard du prophétisme. Qui plus est, la nouvelle maison utilise largement visions et paroles inspirées pour conserver un pouvoir à la légitimité douteuse.

C'est seulement depuis 1369 que cette lignée gouverne le royaume de Castille-Léon : Henri II de Trastamare (1369-1379), bâtard d'Alphonse XI (1312-1350), usurpe alors la couronne, après une longue guerre civile, au terme de laquelle il assassine son demi-frère Pierre $\mathrm{I}^{\mathrm{er}}$ (1350-1369). Pour discréditer l'ancienne dynastie, sa maison met à contribution une vision attribuée à l'aïeul de Pierre $\mathrm{I}^{\mathrm{er}}$, Alphonse X (1252-1284), dont l'affirmation blasphématoire d'avoir pu, à la place de Dieu, créer un monde plus parfait lui avait valu l'apparition d'un ange lui annonçant la révolte de son fils

13. J.-P. BoudET, «Simon de Phares et les rapports entre astrologie et prophétie à la fin du Moyen Age ", Mélanges de l'École française de Rome, 1990, pp. 617-648.

14. Cf. les ouvrages de Bertomeu de Tesben, médecin de Pierre IV, J.-L. Millàs éd., Barcelone, 1962, et J. Vernet, D. Romano, Barcelone, 1957 ; A. Rubió, Documents..., op. cit., t. I, pp. 280-281, t. II, p. 294.

15. Obres completes $i$ selecció de lletres reials per ell redactades, M. de RIQuer éd., Barcelone, 1950, pp. 163-265. Cf. J.-C. SCHMITT, Les revenants, Paris, 1994.

16. Et cum dictus dominus rex esset maximus stronomus et fecisset diversa judicia in meo conspectu et presentia que omnia vera fuerunt, Biblioteca de Catalunya, Barcelone (ci-dessous citée BC), ms 490 f. $100 \mathrm{v}$. 


\section{RITES, MÉMOIRE ET PROPHÉTIES}

Sanche et l'extinction de sa lignée après quatre générations ${ }^{17}$. Cette prophétie est connue, très tôt, en Catalogne : Pierre IV, allié d'Henri II dans la guerre civile de Castille, la rapporte dans sa chronique ${ }^{18}$. Au profit des Trastamare, elle corrobore le caractère maudit d'une dynastie dont le dernier rejeton, Pierre $\mathrm{I}^{\mathrm{er}}$ « le Cruel », est l'objet d'amères critiques de la part des visionnaires franciscains proches de la papauté 19 .

L'installation d'une branche de la nouvelle maison de Castille sur le trône aragonais coïncide avec une période d'intense création prophétique. Comme celle de Pierre I ${ }^{\mathrm{er}}$ de Castille, la cruauté de Pierre IV d'Aragon est montée en épingle par la propagande des Trastamare. Au début du $15^{\mathrm{e}}$ siècle, la prophétie du pseudo-Arnaud de Villeneuve contient cette allusion à son sujet : "Puisque Pierre d'Aragon tua tous ses frères, oncles et cousins, Dieu permit, en raison de ses péchés, qu'aucun de ses successeurs par ligne masculine ne demeurât à la tête du royaume $»^{20}$. Barcelone, cité hostile à Jean II (1458-1479), fils de Ferdinand I ${ }^{\text {er }}$, au cours de la guerre civile qui faillit lui coûter la couronne, est durement critiquée : les prophètes promettent des malheurs, pires qu'à Sodome ou à Babylone, à la ville déloyale ${ }^{21}$. Largement diffusés par les Trastamare, ces thèmes, hostiles à leurs ennemis, assoient définitivement leur pouvoir dans l'esprit de leurs nouveaux sujets ${ }^{22}$.

L'utilisation politique de la prophétie est une pratique largement répandue dans la Couronne d'Aragon à la fin du Moyen Age. Elle coïncide avec l'accroissement du pouvoir et des moyens d'action du roi, capable de diffuser une propagande contribuant à sa victoire dans les guerres qu'il a engagées à l'intérieur et à l'extérieur de son domaine. Elle place le monarque, interprète attitré des paroles des prophètes et des observations des astrologues, dans un monde supérieur, éloigné de ses sujets. Là sont prises, à bon escient, des décisions vitales conditionnant le futur du royaume. Récupéré par le prince, le prophétisme appartient à ces catégories qui permettent de gouverner sans tenir compte des assemblées représentatives, des organes intermédiaires ou des privilèges corporatifs; sa politisation accompagne l'accroissement du pouvoir royal. Dans la confédération catalano-aragonaise, ces vaticinations au service du prince dépassent, d'ailleurs, le cadre étroit des luttes partisanes, pour se situer dans un vaste contexte eschatologique inspiré des tendances extrêmes du franciscanisme.

17. P. Bohigas, "La "visión de Alfonso X" y las "Profecías de Merlín" ", Revista de Filología Española, 1941, pp. 383-398, et «Profecies de Merlí... », art. cité, p. 264.

18. F. Soldevil.a éd., Barcelone, 1971, p. 1124.

19. M. AuRfLl, « Messianisme et prophéties politiques. La péninsule Ibérique à la lumière du Liber Ostensor de Jean de Roquetaillade », Mélanges de l'École française de Rome, 1990, pp. $317-361$.

20. BC, ms 490 , f. $100 \mathrm{v}$.

21. J. Rubió, « Un text català de la "Profecia de l'Ase", de Fra Anselm Turmeda », Estudis universitaris catalans, 1913 , p. 24 ; BC, ms 485, f. 264 v.; et ms 490 , f. 100 r., sans intention péjorative.

22. Jacques II d'Urgell († 1433), concurrent malheureux de Ferdinand $\mathrm{I}^{\mathrm{er}}$ au trône d'Aragon, utilise également les prophéties: Proceso del conde de Urgel, M. de Bofarull éd., dans Colección de documentos inéditos del Archivo de la Corona de Aragón, Barcelone, 18491910, t. XXXVII, pp. 262-269, 275, 292. 


\section{L'attrait du franciscanisme évangélique}

Au $14^{\mathrm{e}}$ siècle, la maison de Barcelone est profondément attachée à l'ordre franciscain (figure 1). Plusieurs de ses rois choisissent d'être enterrés dans ses couvents plutôt que dans le monastère cistercien de Poblet, nécropole dynastique depuis la fin du $12^{\mathrm{e}}$ siècle. Ses reines fondent des communautés de clarisses, où elles prennent le voile au cours de leur veuvage. Quelquesuns de ses infants deviennent mineurs, renonçant, avec éclat, aux honneurs du siècle: tel est le cas de Pierre (1306-1381), fils de Jacques II, qui abandonne le comté de Ribagorça et le dapiférat de Catalogne pour l'ordre franciscain ${ }^{23}$. Plus encore que dans la maison de France de Louis IX, autant que dans la dynastie des Angevins de Naples de Louis de Toulouse, les mineurs exercent une profonde influence sur la spiritualité et sur les pratiques religieuses des rois barcelonais d'Aragon, de Majorque et de Sicile et de leur famille.

Leurs confesseurs sont, pour la plupart, issus de cet ordre ${ }^{24}$. Les franciscains sont appelés à la cour royale, où ils gagnent la confiance du roi et de ses proches parents. Ils jouent parfois, comme Joan Eximeno (13601420), confesseur de Martin ${ }^{\text {er }}$ et de sa famille, un rôle politique bien audelà de leurs attributions spirituelles : ce franciscain majorquin, licencié en théologie par l'université de Toulouse, défend avec acharnement la candidature de Jacques II d'Urgell à la Couronne d'Aragon.

Il est, par ailleurs, le traducteur enthousiaste en catalan de l'Arbor vitae crucifixus d'Ubertin de Casale (1259-1330), tête de file du mouvement spirituel, dont les membres, farouches partisans de la pauvreté absolue, avaient été persécutés par le pape Jean XXII. Peu avant 1404, son confrère Francesc Eiximenis manifeste un intérêt semblable pour cet ouvrage dont il copie de longs passages dans sa Vida de Jesuchrist ${ }^{25}$. Ces idées, propagées par deux confesseurs princiers, encouragent l'observance, la réforme de l'ordre par l'application stricte de la règle primitive : vers 1430, la reine Marie, femme d'Alphonse V (1416-1458), anime avec Matthieu d'Agrigente, prédicateur à succès suivi d'une cohorte de flagellants, ce retour aux sources du franciscanisme ${ }^{26}$. En Catalogne, c'est du sommet de la hiérarchie politique que part la réforme du plus populaire des ordres du Bas Moyen Age.

Ce mouvement de renouveau religieux de la société est l'héritier de la tendance évangélique, très active tout au long du $14^{\mathrm{e}}$ siècle chez les mineurs de la cour. La défense de la pauvreté sans palliatifs et le recours au prophétisme et aux visions, qui caractérisent les franciscains catalans,

23. J. M. PoU, Visionarios..., op. cit., pp. 308-396.

24. J. RuBIÓ, Documents..., op. cit., t. I, pp. 20, 257, 326 ; t. II, pp. 92, 182, 280, 321, 435, 446. Cf. le compte rendu de cet ouvrage par M. BIHL, dans Archivium Franciscanum Historicum, 1924, pp. 152-168.

25. J. M. Pou, Visionarios..., op. cit., pp. 408-409 et 416-445.

26. J. Rubió, « Las cortes de Alfonso el Magnánimo y la espiritualidad del Renacimiento », Estudios sobre Alfonso el Magnánimo, Barcelone, 1960, pp. 153-172. 


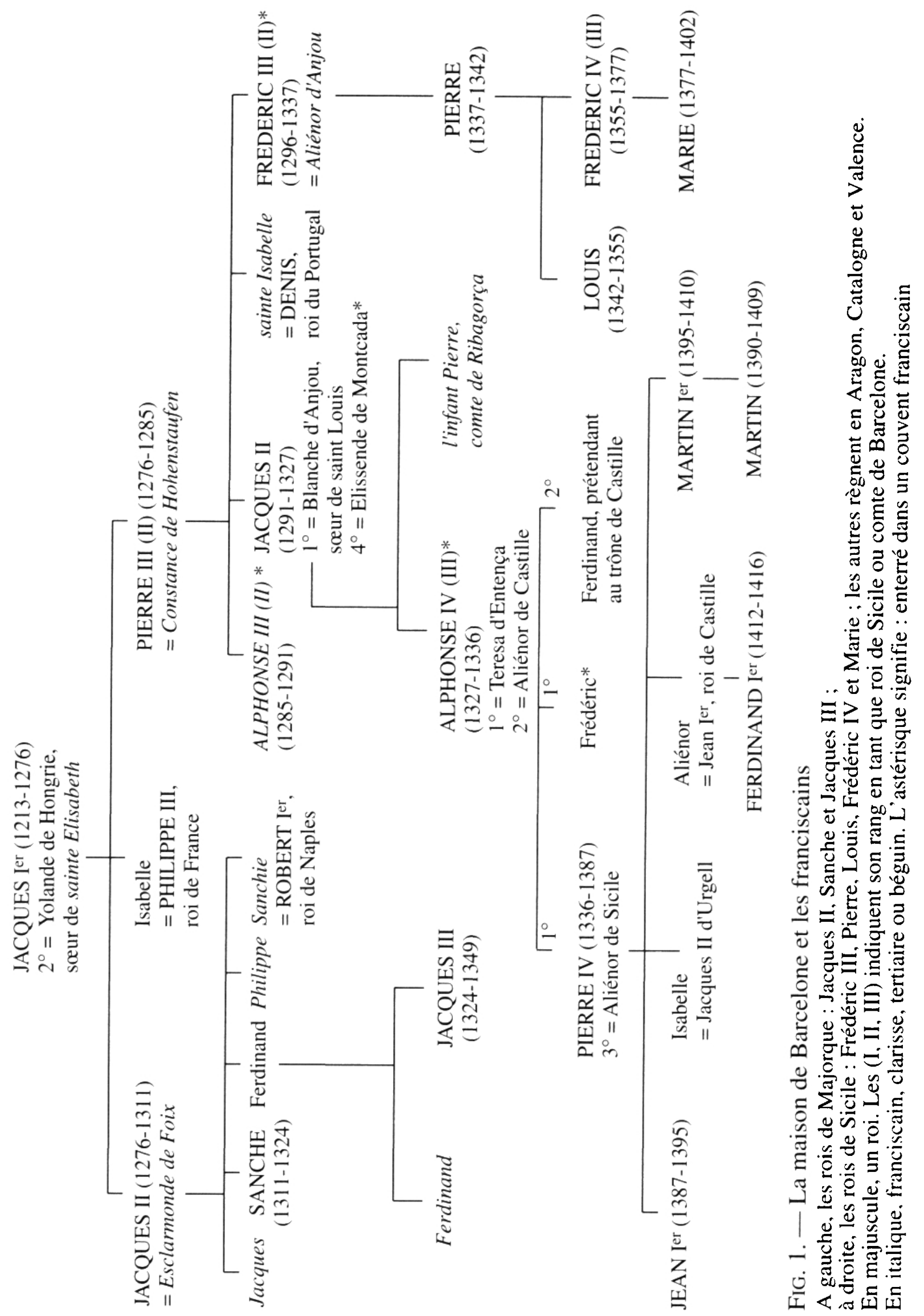


s'inscrit dans le droit fil de l'action menée, autour de 1300, par des spirituels au palais royal même de Barcelone.

L'œuvre d'Arnaud de Villeneuve (1238-1311) détermine, plusieurs décennies durant, l'avenir du franciscanisme de la confédération catalanoaragonaise. Ce médecin, le plus prestigieux de son temps, originaire de Valence, était le familier de Jacques II (1291-1327) d'Aragon et de son frère Frédéric III (1296-1337) de Sicile. Membre du tiers ordre franciscain et défenseur outrancier de la pauvreté évangélique, il rédige, à côté de ses ouvrages médicaux et alchimiques, de nombreux opuscules eschatologiques, prédisant la naissance de l'antéchrist autour de 1368-1378. Son joachimisme, ses diatribes anti-scolastiques et ses critiques contre le clergé séculier lui attirent la méfiance des autorités ecclésiastiques ${ }^{27}$. Ses écrits et ses doctrines sont solennellement condamnés, à titre posthume, par l'archevêché de Tarragone en $1316^{28}$.

Il n'empêche que de nombreux disciples adhèrent à son enseignement. Autour de lui, des notables barcelonais s'organisent en communauté et mettent en pratique sa règle de vie. Ils tiennent un scriptorium pour copier et diffuser ses livres. Ils prêchent la conversion intérieure, s'encourageant à vivre les exigences de la pauvreté et à mépriser les charges honorifiques. Ils prient et veillent à l'approche de leur persécution, prodrome de la fin du monde. Certains embrassent la tierce règle de saint François ou se parent d'habits distinctifs. Comme en Rhénanie, ces béguins, au statut ambigu et indéfinissable, mi-clercs, mi-laïcs, auront vite fait d'éveiller la suspicion de la hiérarchie, qui tente d'éradiquer l'arnaldisme sous Jean XXII ${ }^{29}$.

Les archives notariales et royales de Barcelone livrent leur nom, leur métier et leur rang social : Pere Jutge, marchand et apothicaire, conseiller municipal, est connu de Jacques II qui le dispense de service militaire ; Pere de Montmeló, officier royal spécialisé dans les affaires de la mer, sous-viguier de Gérone, possède son propre navire; Jaume des Pla est scribe dans la maison royale; Miquel Artiga reçoit le notariat du bailliage de Barcelone en raison des multiples services rendus à Alphonse III ; Bernat Llimona exerce la médecine ${ }^{30}$. Les élites urbaines de Barcelone sont bien

27. Pour une vision globale du problème des rapports conflictuels entre le prophétisme et les intellectuels universitaires, cf. A. VAUCHEZ, «Les théologiens face aux prophéties à l'époque des papes d'Avignon et du Grand schisme ", Mélanges de l'École française de Rome, 1990, pp. 577-588, et A. de LiBtra, Penser au Moyen Age, Paris, 1991, pp. 133-136.

28. Une mise au point récente de la biographie et de l'activité prophétique d'Arnaud de Villeneuve dans H. LeE, M. E. ReEves, G. Silano, Western Mediterranean Prophecy. The School of Joachim of Fiore and the Fourteenth Century, Toronto, Breviloquium, 1989, pp. 2746, ainsi que J. Penarnau, "Noves dades biogràfiques de mestre Arnau de Valanova », Arxiu de textos catalans antics, 1988-1989, pp. 276-282, et «L'Allocutio Christiani... d'Arnaud de Vilanova ", ibid., 1992, pp. 7-135.

29. Dans un contexte certes différent sur le plan social et institutionnel, cf. des remarques concordantes sur ces "marginaux de l'entre-deux », dans J.-C. SCHMITT, Mort d'une hérésie. L'Église et les clercs face aux béguines et aux beghards du Rhin supérieur du XIV au $X V^{\prime}$ sieccle, Paris, 1978, pp. 35 et 203.

30. J. Perarnau, $L$ ' a alia informatio beguinorum "d'Arnaud de Vilanova, Barcelone, 1976, pp. 112-120. 


\section{RITES, MÉMOIRE ET PROPHÉTIES}

représentées parmi les disciples d'Arnaud de Villeneuve. Officiers royaux et scribes, mais aussi médecins et apothicaires au service du roi et de sa maisonnée, ils diffusent, comme les confesseurs franciscains, l'évangélisme dans le palais princier.

L'exercice du commerce par plusieurs de ces béguins rend, toutefois, leur salut assez aléatoire. Dans les mentalités communes, de nombreux préjugés s'attachent, en effet, aux activités marchandes qui font la fortune facile de ceux que l'on perçoit, sous un jour péjoratif, comme des affairistes et des trafiquants. Leur rapport au temps - critiqué traditionnellement comme le vol des profiteurs qui s'enrichissent de son écoulement grâce au prêt à intérêt ${ }^{31}$ - n'est, d'ailleurs, pas indifférent à leur joachimisme, leur conception linéaire de l'histoire, pensée comme un progrès vers l'accomplissement d'un troisième âge paradisiaque du Saint-Esprit qui ne saurait tarder : il contraste avec la conception christocentrique de l'Église dont les catégories temporelles sont centrées sur l'avènement accompli du Sauveur, alpha et oméga, récapitulant en lui toute chose. Le lien qui unit le commerce pratiqué par les membres de la communauté d'Arnaud et leur perception hétérodoxe du temps explique, en partie, leur rejet.

Les franciscains sont, néanmoins, là pour réhabiliter leur profession, comme il ressort d'un texte célèbre de Francesc Eiximenis, rédigé entre 1385 et 1386 à l'adresse des conseillers municipaux de Valence : « La terre où transitent d'abondantes marchandises est toujours riche, fertile et pacifiée. Les marchands doivent donc être aidés plus que les autres laïcs. Ils sont la vie de la terre, le trésor de la république, la nourriture des pauvres, le bras de toute bonne affaire et la perfection de toute chose. Sans marchands, les communautés déclinent, les princes deviennent des tyrans, les jeunes se perdent et les pauvres pleurent. Les chevaliers et les rentiers ne font pas de grandes aumônes, contrairement aux marchands, pères et frères de la chose publique $»^{32}$. Le discours d'Eiximenis traduit une sympathie évidente envers la bourgeoisie montante au sein de laquelle il réalise, comme tant de frères mineurs, son apostolat.

Plus que sur Jacques II, l'influence d'Arnaud de Villeneuve et de sa doctrine se fait sentir sur Frédéric III, dont il devient le mentor dans la mise en œuvre d'un vaste programme de réforme de la société sicilienne ${ }^{33}$. Protecteur d'Ubertin de Casale et des autres rescapés spirituels des persécutions de Jean XXII, le roi de Trinacrie travaille au renouveau religieux de la Sicile dans un contexte millénariste. Il proclame un code législatif compilé par Arnaud imposant les exigences de la pauvreté stricte dans tout son royaume. Il demande à ses courtisans une vie austère, qu'il prêche par l'exemple de sa propre pénitence : sa femme vend, sous le conseil d'Arnaud

31. J. LE Goff, «Au Moyen Age : temps de l'Église et temps du marchand », réédité dans Pour un autre Moyen Age, Paris, 1977, pp. 46-65.

32. El Dotzé del Chrestià o Regiment de princeps e de comunitats, D. de MOLINS DEL REI éd., Regiment de cosa pública, Barcelone, 1927, p. 168.

33. H. BresC, «Un comté pour les pauvres (Modica, 1337)», Mélanges Michel Mollat, Paris, 1987, pp. 267-276. 
de Villeneuve, ses bijoux. L'équité et la justice, surtout à l'égard des pauvres, deviennent les valeurs suprêmes de l'État. Les nécessiteux et les forains sont protégés par les autorités; des hôpitaux sont construits pour les Grecs razziés par les mercenaires catalans ; la manumission des esclaves est encouragée ; la pratique de la conversion forcée des musulmans siciliens est proscrite. L'évangélisme militant d'Arnaud de Villeneuve quitte ainsi le domaine des élucubrations théoriques : il se concrétise dans l'île par la poursuite de la politique volontariste de Frédéric II.

A la même époque, des attitudes spirituelles déterminent la vocation de quelques membres de la maison de Majorque qui rejettent honneurs et richesses de façon fracassante. Cette voie est suivie par deux des fils de Jacques II (1276-1311), protecteur du tertiaire missionnaire Raymond Lulle, naguère son précepteur et son sénéchal : en 1299, Jacques $(† 1306)$ devient franciscain, renonçant à son aînesse et au mariage stipulé avec Catherine de Courtenay, héritière de Byzance ${ }^{34}$; c'est en commun accord avec Louis d'Anjou, son ami intime, longtemps captif en Catalogne, qu'il prend cette décision. Son exemple est suivi par son frère Philippe (1288-1343) qui, ordonné prêtre vers 1305, décline l'offre de l'épiscopat de Mirepoix pour promouvoir la stricte pauvreté parmi ses disciples. Sanchie († 1345), autre enfant de Jacques II, femme de Robert ${ }^{\text {er }}$ de Naples, fondatrice de plusieurs couvents de clarisses dans cette ville, est alors une partisane ouverte de Michel de Cesène, le ministre général de l'ordre franciscain démis de ses fonctions pour son attachement aux rigueurs de la pauvreté. Les membres de la maison de Majorque adhèrent au franciscanisme spirituel.

Tandis que Frédéric III promeut l'expérience évangélique en Sicile, Philippe de Majorque, son cousin germain, mène une action similaire dans les Baléares. Tuteur du futur Jacques III (1324-1349) depuis 1318, il essaye d'instaurer le programme du renouveau spirituel par la pauvreté dans son île. A la cour de Palma, il installe son entourage de béguins que l'un de ses membres, le noble roussillonnais Aimar de Mosset, définit en 1333, devant l'inquisiteur Jacques Fournier, comme « les frères encapuchonnés de la tierce règle de la familia de Philippe ». Les idées de ces personnages sont inspirées par les lettres et par la fréquentation d'Ange Claréno, supérieur des ermites célestins, auteur du libelle intitulé Histoire des sept tribulations de l'ordre des mineurs. Elles traduisent une nette influence du franciscanisme spirituel : culte de la pauvreté et croyance joachimite en l'imminence de l'avènement du troisième âge, où seuls survivront les plus fidèles disciples de saint François.

Séduit par cet enseignement, l'infant Ferdinand émet le vœu de devenir franciscain : son frère Jacques III semble avoir également voulu suivre cette résolution, comme il ressort de la lettre de 1322 par laquelle Jean XXII sermonne Philippe pour appliquer des méthodes indignes à l'éducation d'un futur roi. La pression de ce pape pousse, enfin, Philippe et ses disciples à quitter les Baléares pour Naples, où Sanchie les accueille avec Ange Claréno, qui y a trouvé refuge dans la persécution qui s'abat désormais sur les

34. Ramon Muntaner, Crònica, F. Soldievil.A éd., Barcelone, 1962, p. 831, § 182. 


\section{RITES, MÉMOIRE ET PROPHÉTIES}

spirituels. Philippe mène, dans des terres dont sa sœur est la reine, une vie de mendiant et prêche contre les bulles de Jean XXII hostiles à la pauvreté stricte des franciscains. En 1340, peu avant sa mort, il échoue dans sa tentative de faire approuver par Benoît XII sa fondation, l'ordre des Frères de la vie pauvre ${ }^{35}$. La papauté rejette ses idées.

Le déclenchement de la persécution de 1316 contre les spirituels ouvre, aux yeux de beaucoup, le début du troisième âge : le sixième sceau de l'Apocalypse est brisé et une nouvelle ère, paisible et prospère sous la conduite des franciscains fidèles à la pauvreté, va bientôt être instaurée sur terre. Dans ce renouveau qui se substitue à la décadence ancienne, l'Église charnelle est périmée. La persécution qu'elle mène contre fraticelles et béguins confirme sa corruption, tout comme elle accroît la purification par la souffrance de ceux qui demeurent attachés à la règle primitive de saint François ${ }^{36}$.

Elle justifie la contestation à la papauté avignonnaise par les dissidents spirituels et par des monarques qui, comme l'empereur Louis de Bavière (1314-1347) ou Frédéric III, rêvent à des États organisés d'après la seule loi de l'Évangile. La maison de Barcelone, dans ses trois branches d'Aragon, de Majorque et de Sicile, se fait l'écho de ce courant idéologique. Certains de ses membres instaurent même des utopies insulaires dans leurs domaines, reproduisant le programme évangélique cher aux fraticelles qui trouvent refuge auprès d'eux, tandis que durcit la persécution.

Dans le nord de l'Italie, les tendances spirituelles donnent souvent lieu à des expériences érémitiques, loin du monde dans lequel les frères mineurs sont, par la prédication et l'exemple, censés exercer leur apostolat. Dans les principautés de la Couronne d'Aragon, en revanche, elles s'enracinent profondément en milieu urbain. Les marchands - qui manient ces mêmes pièces de monnaie devenues indispensables aux fraticelles rejetant, dans leur mendicité, toute propriété foncière - sont sensibles au discours évangélique : ils fondent des communautés de béguins attachés à la pauvreté absolue, revêtent l'habit tertiaire et font personnellement l'expérience de la spiritualité franciscaine. Ces hommes, dont le commerce est l'activité vitale, appartiennent au puissant groupe de pression qui détermine largement l'impérialisme maritime de la maison princière. Ils ont leurs entrées à la cour, où ils assument souvent des offices. La thalassocratie de la royauté aragonaise est encouragée par des marchands idéologiquement proches de ces mêmes spirituels franciscains que la famille princière choisit pour confesseurs et pour conseillers. La diffusion d'un prophétisme d'inspiration joachimite favorable à la maison de Barcelone, puis aux Trastamare, est déterminée par l'étroitesse des liens qui associent le roi d'Aragon, les marchands et les franciscains.

35. J. M. PoU, Visionarios..., op. cit., pp. 111-149.

36. A. Catenave, «La vision eschatologique des spirituels franciscains autour de leur condamnation ", The Use and Abuse of Eschatology in the Middle Ages, W. Verbekt, D. Verhelst, A. WelKehuYSEe éds, Louvain, 1988, pp. 393-403. 


\section{La fascination des spirituels languedociens}

De la semence de Frédéric et de la maison d'Aragon, au temps où cette tempête s'abattra sur l'Église, à l'ouverture du sixième sceau, un roi, le quatrième depuis Frédéric II, surgira dans sa maison, auquel s'allieront, par la volonté divine, dix maisons de rois chrétiens, avec lesquelles il se lèvera contre le roi de France, qu'il humiliera tellement qu'il réduira presque à néant, au point qu'il n'y aura plus aucun espoir pour lui. Le père très saint révéla aussi à ses compagnons, et spécialement à frère Léon, que le dit prince obtiendrait l'empire romain et qu'il gouvernerait soudain presque tout le monde ${ }^{37}$.

Cette prophétie qu'on disait inspirée, sur le mont Alverne, à saint François d'Assise, qui la révéla ensuite à frère Léon, connaît une diffusion considérable, tout particulièrement dans le sud de la France. Elle est explicitement citée par le mineur languedocien Pierre Jean-Olieu (1248-1298) dans sa Lecture de l'Apocalypse et par Jean de Roquetaillade (1310-1365), dans son principal ouvrage, le Livre révélateur $(1356)^{38}$. Prédisant la ruine, malheureuse à leurs yeux, de la maison de France, annihilée par un descendant aragonais de Frédéric II (1197-1250) de Hohenstaufen, elle reprend des thèmes chers aux premiers imitateurs italiens de Joachim de Flore.

Un personnage occupe une place clef dans le complexe système eschatologique de l'abbé calabrais : l'Empereur des derniers temps. Cet antéchrist politique est le pendant de l'antéchrist ecclésiastique, un pseudo-pape : le tyran et le faux pontife sont, respectivement, Néron et Simon le Magicien, la bête de la mer et la bête de la terre prophétisées par l'Apocalypse. Grégoire IX (1227-1241) désigne Frédéric II comme l'antéchrist impérial dans des bulles et lettres, dont l'une porte le titre significatif d'Ascendit de mari bestia (1239). Les guelfes italiens récriminent contre le Souabe dans des termes similaires. Le Super Hieremiam (1240), un opuscule prophétique faussement attribué à Joachim, s'en prend à la postérité d'Henri VI (11901197), premier empereur germanique devenu maître de la Sicile, représentant de ces rois destructeurs du Nord dont l'image est la vipère, la couleuvre et le dragon volant. Des cisterciens et des franciscains joachimites, favorables à la papauté dans sa lutte contre les Hohenstaufen, se font l'écho de ces thèmes ${ }^{39}$.

En 1250, la mort de Frédéric II déçoit bien des millénaristes, convaincus de la mission eschatologique qu'il aurait dû accomplir de son vivant. Beaucoup le croient réfugié, à la place d'Arthur, dans l'Etna, le volcan

37. A. Fierens, «La question franciscaine. Le manuscrit II 2326 de la Bibliothèque royale de Bruxelles ", Revue d'Histoire ecclésiastique, 1909, p. 55. Autre version, dans un manuscrit aujourd'hui perdu, citée par P. BoHIGAS, «Profecies catalanes... », art. cité, p. 35, n" 16.

38. R. Manselli, La "Lectura super Apocalipsim» di Pietro di Giovanni Olivi, Rome, 1955 , p.224 ; N. BÉRIOU, «Saint François, premier prophète de son ordre, dans les sermons du XIII" siècle », Mélanges de l'École française de Rome, 1990, p. 536.

39. R. E. LeRner, «Frederick II, Alive, Aloft, and Allayed in Franciscan-Joachite Eschatology », The Use and Abuse..., op. cit., pp. 359-384. 


\section{RITES, MÉMOIRE ET PROPHÉTIES}

sicilien où se trouve l'entrée de l'enfer et du purgatoire ${ }^{40}$. D'après une addition à la Vaticination de la sybille Érythrée (1249), il doit revenir, incarné dans l'un de ses descendants, accomplir les châtiments prévus par la Providence à la fin des temps. Pour le Liber de oneribus prophetarum (1255-1256), ce Fredericus redivivus n'est autre que Frédéric d'Antioche, son fils bâtard, tandis que le cardinal cistercien John Tolet envoie, en 1269, une prophétie à Erfurt, affirmant qu'un membre de la postérité de Frédéric obtiendra l'union des Espagnols et des Allemands pour anéantir le roi de France $^{41}$.

En 1268, Conradin, dernier descendant masculin de Frédéric II, vient

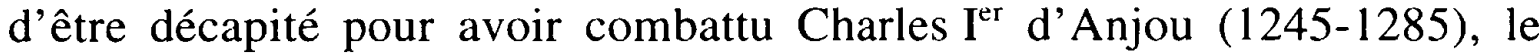
frère de saint Louis qui a obtenu la Sicile avec l'appui du Saint-Siège. Constance de Hohenstaufen, petite-fille de Frédéric II, devient son héritière ; en 1282, elle fomente, avec son mari Pierre III (1276-1282) d'Aragon, une révolte anti-angevine en Sicile où le Barcelonais est proclamé roi. Au lendemain des Vêpres, les Catalans deviennent la cible des pseudo-joachimites guelfes de la fin du $13^{\mathrm{e}}$ siècle qui leur réservent le rôle de l'antéchrist et les métaphores reptiliennes qu'ils accordaient, quelques décennies auparavant, à Frédéric II.

Venue d'outre-monts, cette tradition prophétique, hostile aux maisons de Souabe et d'Aragon, est reprise par les spirituels occitans. Le franciscain Hugues de Digne (1205-1257), ministre de Provence, l'a peut-être transmise oralement à ses disciples. Il possède de nombreux ouvrages joachimites qui le familiarisent avec le thème du rejet de Frédéric II $^{42}$. Il défend, en outre, la pauvreté dans l'ordre. Son rayonnement est grand: sa sœur Douceline s'inspire de ses idées pour ouvrir un béguinage à Hyères, puis à Marseille ; il est entouré de laïcs qui sont, d'après le témoignage de Salimbene d'Adam, des « juges, notaires, médecins et autres lettrés ${ }^{43}$. Arnaud de Villeneuve, demeurant longtemps à Marseille, les a fréquentés : la communauté qu'il organise à Barcelone s'en inspire largement.

Mais le principal disciple d'Hugues de Digne est Pierre Jean-Olieu qui, même s'il ne l'a pas rencontré personnellement, connaît à la perfection son œuvre dont il cite de longs extraits. Défenseur acharné de l'usus pauper, la pauvreté réellement vécue au-delà du simple détachement d'esprit, joachimite et anti-aristotélicien, prédicateur enflammé, auteur d'une soixantaine de traités, ce franciscain languedocien est le maître à penser de toute une génération de spirituels. Empruntant à Joachim de Flore le principe de la dualité de l'antéchrist, il forge de toutes pièces l'expression «antéchrist mystique » pour désigner un faux pape, persécuteur de la pauvreté évan-

40. J. LE GoFf, Naissance du purgatoire, Paris, 1981, pp. 276-277 et 420-421.

41. R. E. LERNER, «Frederick ... », art. cité, pp. 372-373 ; M. W. BloOMFIELD, M. E. REEVES, «The Penetration of Joachimism into Northern Europe », Speculum, 1954, pp. 790-791; MGH, SS, t. XXVI, p. 207.

42. R. RuSCONI, «A la recherche des traces authentiques de Joachim de Flore dans la France méridionale ", Cahiers de Fanjeaux, 1992, pp. 63-80.

43. J. Paul, « Hugues de Digne », Cahiers de Fanjeaux, 1975, pp. 69-98 et « Le commentaire d'Hugues de Digne sur la règle franciscaine ", Revue d'Histoire de l'Église de France, 1975, pp. 231-241. 
gélique, fauteur du schisme, de l'hérésie et de la rébellion. Frédéric II, la tête blessée à mort d'Apocalypse XIII, 3, «qui revivra dans quelqu'un de sa race », sera son allié : ce personnage ne pourra être issu que de la postérité de Pierre III, responsable des innombrables conflits qui, depuis son invasion de la Sicile, se sont abattus sur l'Occident. Il précédera le vrai antéchrist qui mourra en 1335 ; une période de grâce et de paix sera alors instaurée ${ }^{44}$.

Ces développements répondent aussi bien à la lecture des pseudojoachimites qu'à l'attachement à la dynastie angevine de Naples, ennemie de la maison de Barcelone en Sicile : Pierre Jean-Olieu tente, en effet, de se rendre auprès de Louis d'Anjou et de ses frères, otages en Catalogne à la place de leur père Charles II (1285-1309), capturé au cours d'une bataille navale au large de Naples en 1284. Il leur écrit une longue lettre; son enseignement est décisif dans la vocation de Louis. A sa mort, Jean-Olieu jouit d'un prestige considérable parmi les partisans de la règle primitive de saint François. Son tombeau devient un haut lieu de pèlerinage.

Son cuvre marque considérablement celle de Jean de Roquetaillade, qui a dû rencontrer ses disciples au cours de ses études à l'université de Toulouse $^{45}$. Ce visionnaire exalté, précurseur de l'observance, est incarcéré, dans les années 1350-1360, au palais des papes d'Avignon où il suit avec passion l'actualité politique. Ses ouvrages, remplis d'allusions aux événements de son temps, sont un jalon capital dans le processus de politisation du prophétisme. Ils témoignent d'un sentiment patriotique précoce à l'égard de la maison de France et de ses branches collatérales : «Les Francs, surtout de la Gaule et des Pouilles, ont été unis, depuis des temps immémoriaux, dans leur amour immense pour les recteurs de l'Église universelle et romaine », écrit-il.

L'admiration qu'il éprouve pour les Angevins de Naples le pousse à rejeter avec véhémence la maison concurrente d'Aragon, issue de la semence de Frédéric II, le pseudo-empereur. Deux antéchrists, l'un oriental et l'autre occidental, ruineront bientôt la terre : le premier est présenté sous les traits de la secte de Mahomet, tandis que le second pourrait bien être le roi d'Aragon. Dans son Livre des secrets, Roquetaillade affirme que Louis de Trinacrie (1342-1355), petit-fils de Frédéric III, incarnera bientôt ce personnage clef de la fin des temps. Dans le droit fil du joachimisme guelfe, les rois d'Aragon et de Sicile, issus de la race frédéricienne, prennent sous sa plume le visage de l'antéchrist ; chez lui, ils éveillent autant la méfiance que la crainte révérencielle ${ }^{46}$.

44. G. Barone, «L'œuvre eschatologique de Pierre Jean-Olieu et son influence. Un bilan historiographique ", Cahiers de Fanjeaux, 1992, pp. 49-61 ; H. LeE, M. E. ReEves, G. Sil.ANO, Western..., op. cit., pp. 17-26.

45. Sur ce personnage, cf. J. Bignami-OditR, «Jean de Roquetaillade (de Rupescissa)», Histoire littéraire de la France, t. XLI, Paris, 1981, pp. 75-240, ainsi que les travaux des participants à l'URA 1011 , et notamment S. BARNAY, "L'univers visionnaire de Jean de Roquetaillade », Cahiers de Fanjeaux, 1992, pp. 171-190.

46. M. Aurell, «Prophétie et messianisme politique. La péninsule Ibérique au miroir du Liber Ostensor de Jean de Roquetaillade », Mélanges de l'École française de Rome, 1990, pp. 317-361. 


\section{RITES, MÉMOIRE ET PROPHÉTIES}

Or ses livres connaissent, de façon paradoxale, un succès considérable en Catalogne, où ils sont maintes fois copiés, traduits et cités. C'est dans l'entourage du roi d'Aragon qu'ils sont le plus souvent lus. Ils auraient, cependant, pu être utilisés de façon subversive, pour mettre en question la domination de la maison de Barcelone, incarnation de la bête néfaste de l'Apocalypse. Mais dans des terres où son pouvoir est solidement établi et où les mouvements contestataires à nature eschatologique ne sont pas à craindre, ils servent plutôt ses intérêts, accordant à la royauté une dimension messianique.

L'antéchrist est ambivalent parce qu'il ressemble au Christ, dont il précède de peu la parousie. Même si elle prépare sa chute irréparable, son hypocrisie le rend pareil à lui, du moins dans les apparences. Il est l'agent de la Providence et l'exécuteur des châtiments nécessaires. Par cette terrifiante fonction, il apparaît beaucoup plus proche de l'ange exterminateur que de Satan. Il provoque un sentiment de fascination qui ressemble davantage à la terreur sacrée qu'à la haine.

Le pape Grégoire IX affirma, un jour, que Frédéric II aimait bien s'entendre traiter d'antéchrist ${ }^{47}$. Il y a de fortes chances pour que cette assertion relève davantage du renseignement obtenu à la bonne source que du pieux mensonge visant à discréditer son ennemi. On sait, en outre, toute la protection que l'Empereur accorda aux ordres mendiants, du moins jusqu'aux années 1240, spécialement aux frères mineurs, pour la plupart convaincus de la véracité des prophéties joachimites ${ }^{48}$. Bien que favorable à son père Henri VI, Joachim de Flore lui-même n'avait-il pas présenté l'Empire romano-germanique comme la tête du dragon et comme Babylone? Le franciscain Thomas de Pavie se faisait, dans les Distinctiones (1246), son porte-parole, avançant que l'antéchrist issu de la race frédéricienne écraserait les rois infidèles du Maroc, de la Tunisie, de l'Égypte et de la Perse ${ }^{49}$. Ce discours témoigne de toute l'ambiguïté dans la perception de l'antéchrist, tyran satanique certes, mais promis à la monarchie universelle après avoir vaincu les païens et les musulmans.

Au $13^{\mathrm{e}}$ siècle, la diffusion de prophéties joachimites par les franciscains guelfes n'entrave pas nécessairement l'action de Frédéric II et de ses descendants. Parce qu'elles les placent dans un monde sacré, leur octroyant un pouvoir de destruction surnaturel, bien supérieur à leurs ennemis respectueux de la papauté, ces vaticinations servent, au fond, la propagande politique des Hohenstaufen. Au lendemain de 1282, les franciscains catalans utilisent, sans gêne, le matériau prophétique légué par les spirituels italiens

47. E. KantorowiCZ, L'empereur Frédéric II, Paris, 1987, p. 547, et, plus généralement, sur l'ambiguïté de l'Antéchrist, être suprahumain, déchaînant les forces les plus sauvages et terribles, fléau de Dieu et marteau du monde, pp. 543-621. Cf. un essai suggestif, extrêmement éclairant sur la signification de cet ouvrage: A. Boureau, Histoire d'un historien. Kantorowicz, Paris, 1990.

48. G. Barone, «Federico II di Svevia e gli Ordini Mendicanti », Mélanges de l'École française de Rome, 1978, pp. 607-626.

49. E. Longré, «Les "Distinctiones" de Fr. Thomas de Pavie, o. f. m. », Archivium Franciscanum Historicum, 1923, p. 27. 
et languedociens, en apparence hostile à la maison de Barcelone, afin d'exalter le messianisme de leurs maîtres, héritiers idéologiques de Frédéric II. Le joachimisme, détourné de ses premiers choix pontificaux et angevins, devient une arme redoutable entre les mains des rois d'Aragon et des fraticelles de leur cour.

\section{Une affirmation symbolique : bestiaire et onomastique}

Le $14^{\mathrm{e}}$ siècle, et plus particulièrement le long règne de Pierre IV (13361387), est une période d'affirmation de la Couronne d'Aragon qui poursuit son expansion maritime et qui s'attaque aux prérogatives de ses principautés. Le roi, chaque jour plus puissant, tente de s'imposer dans l'imaginaire politique de ses sujets. Des symboles et des emblèmes, attachés à sa personne, sont proposés à la collectivité : éléments d'un vaste système de propagande, ils devraient gagner la fidélité de tous envers le roi, prévention raisonnable à une époque de ligues nobiliaires, de contestation municipale et de révoltes insulaires ; marqueurs identitaires d'une collectivité, ils servent à souder les territoires disparates de la confédération catalano-aragonaise dans un sentiment de cohésion qui relève davantage du loyalisme envers la royauté que du patriotisme. C'est dans le prophétisme joachimite que la maison de Barcelone trouve un stock d'abondants symboles, riche en figures et en thèmes susceptibles d'augmenter son éclat.

\section{De l'Apocalypse au cimier: le dragon volant et la chauve-souris}

Le dragon ailé est l'un de ces emblèmes chers à la royauté aragonaise : la ressemblance phonétique — «dragon », «d'Aragon» - en fait une figure parlante, toute prédestinée, pour ses armoiries. Au milieu du $14^{\mathrm{e}}$ siècle, où la mode des cimiers, venue de France, se répand dans la péninsule Ibérique, Pierre IV place ce saurien sur son heaume : il apparaît, pour la première fois, dans l'image équestre de l'avers de l'un de ses sceaux daté de 1343 ou $1344^{50}$. En 1378, le bas-relief, que ce monarque fait graver sur la porte de ses appartements au monastère de Poblet, représente le casque avec le dragon volant sur son écu soutenu et timbré (figure 2). Ce cimier est devenu un attirail indispensable sur le heaume de tous les rois et des infants d'Aragon (figure 3).

Des motivations personnelles ont certainement déterminé le choix que Pierre IV fait de cet animal imaginaire comme mascotte de sa maison: les historiens ont avancé la faible taille de roi, compensée par le port d'un haut cimier, ou l'imitation de son beau-père Philippe III (1328-1343) de Navarre-Évreux qui avait adopté un emblème semblable. Eulàlia Duran a naguère cherché les origines de cet emprunt dans les bestiaires d'inspiration orientale, représentant le lézard volant de Malaisie, animal bienfaisant qui conviendrait davantage à la dynastie royale que la bête maléfice de

50. F. de Sagarra, Sigillografia catalana, Barcelone, 1916, t. I, p. 214, n' 59, et planche XXXI. 


\section{RITES, MÉMOIRE ET PROPHÉTIES}

Fig. 2. - Poblet (sud de la Catalogne), bas-reliefs sculptés

En haut, sur la porte des tours royales du monastère, à l'époque de Pierre IV porte principale du palais royal. Ecu de Martin Ier, deux anges tiennent le dragon
En bas, au-dessus de la
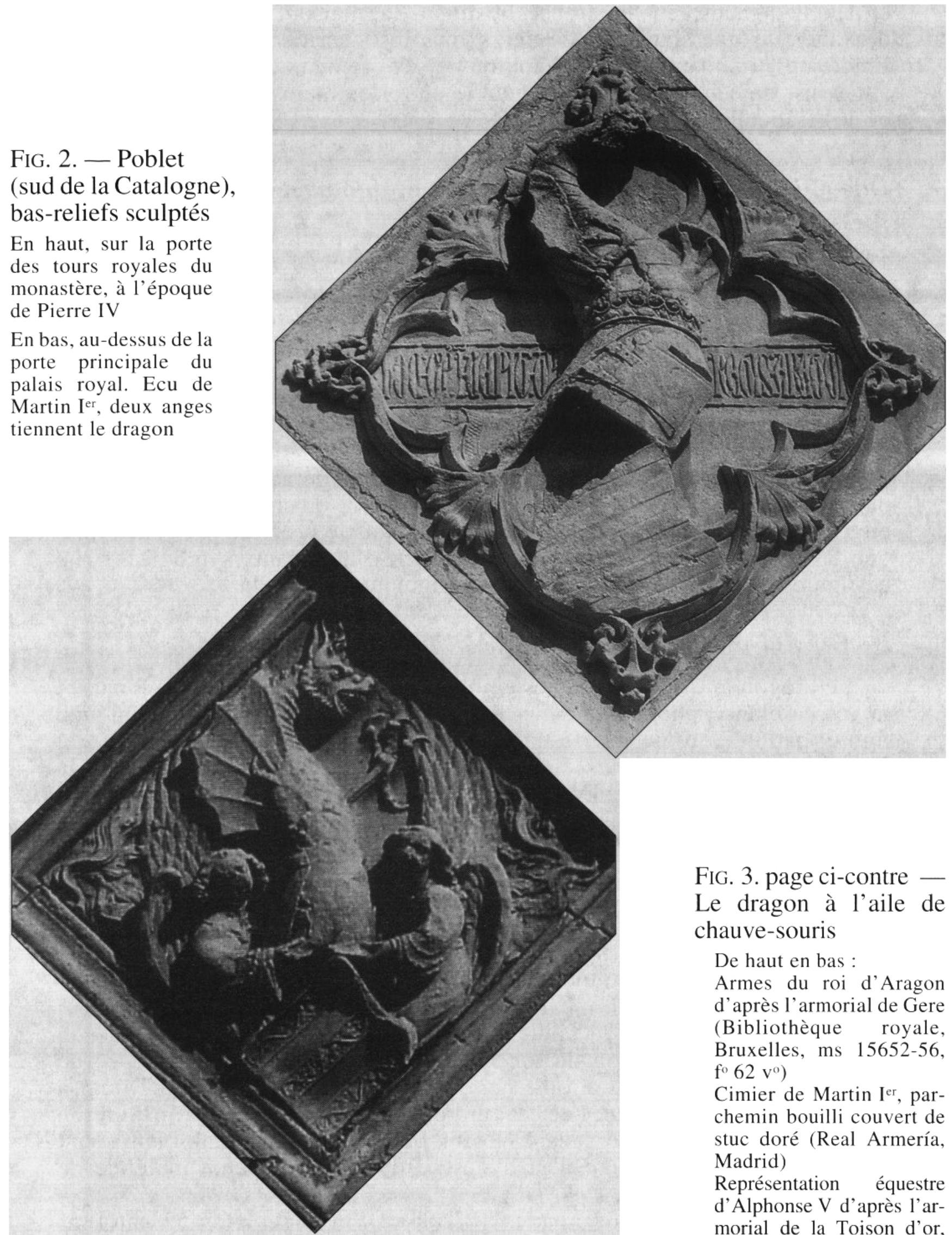

FIG. 3. page ci-contre Le dragon à l'aile de chauve-souris

De haut en bas :

Armes du roi d'Aragon d'après l'armorial de Gere (Bibliothèque royale, Bruxelles, ms 15652-56, fo $62 \mathrm{v}^{\circ}$ )

Cimier de Martin Irer, parchemin bouilli couvert de stuc doré (Real Armería, Madrid)

Représentation équestre d'Alphonse V d'après l'armorial de la Toison d'or, $\mathrm{XV}^{\mathrm{e}}$ siècle (Bibliothèque de l'Arsenal, Paris, ms 4790, fo 108) 


\section{RITES, MÉMOIRE ET PROPHÉTIES}

l'Apocalypse; elle se fonde sur le fait que, en 1343 - l'année où l'on coule, pour la première fois, la matrice du sceau du roi avec le cimier au dragon ailé - , les Valenciens instaurent la fête de Georges, saint sauroctone. Cet auteur conclut : "Les camps du bien et du mal étaient ainsi bien départagés $»^{51}$. Cette explication est, au demeurant, séduisante, mais ni le dragon terrassé par saint Georges n'est la bête de l'Apocalypse, ni des sources catalanes ne permettent, au $14^{\mathrm{e}}$ siècle, d'établir la prétendue jonction avec la zoologie de l'Extrême-Orient.

En revanche, il existe quelques manuscrits accordant à Pierre IV une mission proche de l'antéchrist. En outre, dans l'imaginaire politique de la lignée issue de Frédéric II, l'empereur pour qui la haine et la vengeance étaient des vertus, la guerre, fin justifiant trop souvent des moyens peu avouables, broie les cartes classiques de la nette séparation entre le bien et le mal, tandis que les prises de position partisanes de la papauté poussent les Barcelonais à la dissidence. Enfin, partout en Occident, le cimier - qui reprend, dans une expression convulsive, des bêtes infernales, péjoratives ou monstrueuses, qu'on n'ose pas introduire dans l'écu - est un masque, double visage qui permet la transgression, ludique ou diabolique : le guerrier s'identifie à l'animal terrifiant de son heaume, dont la fonction est d'effrayer l'adversaire ${ }^{52}$. Force est donc de revenir à la thèse traditionnelle d'Andreu Ivars qui avait affirmé, déjà en 1923, la dimension apocalyptique du dragon volant du cimier de Pierre IV et des siens ${ }^{53}$.

Empruntée à Isaïe, Daniel et l'A Apocalypse, l'image du dragon ailé revient souvent dans les écrits des pseudo-joachimites de la fin du $13^{\mathrm{c}}$ siècle. L'expression regulus volans (Is XXX, 6), citée par le Super Hieremiam (1240), donne lieu à un jeu de mots entre le «basilic » et le « roitelet », que son auteur applique à Frédéric II. Le De oneribus prophetarum (1250) voit également en l'empereur le regulus volans d'Isaïe, ainsi que le dragon aux sept têtes et aux dix cornes poursuivant la femme d'Apocalypse XII ; il prédit l'avènement d'un troisième Frédéric aux propriétés aussi surhumaines. De façon semblable, le Super Esaiam (1260) s'en prend aux Hohenstaufen, aigle, serpent et tête du dragon ${ }^{54}$. Les joachimites guelfes dénigrent Frédéric II et les siens sous les traits de cette bête apocalyptique, en lutte ouverte contre l'Église.

Le saurien passe à la maison de Barcelone avec le legs des Hohenstaufen. Entre 1294 et 1303, l'Oracle de Cyrille (1294-1303) est rédigé, peut-être dans l'entourage d'Ange Claréno, et retouché par Arnaud de Villeneuve. On prétend que cette prophétie, gravée sur des plaques d'argent, fut donnée

51. E. DuRan, Simbologia política catalana a l'inici dels temps moderns. Discurs llegit el dia 10 de desembre de 1987 en l'acte de recepcío pública a la reial Academia de Bones Lletres de Barcelona, Barcelone, 1987, p. 11.

52. M. Pastoureau, «Du masque au totem: le cimier héraldique et la mythologie de la parenté à la fin du Moyen Age », Razo, 1986, p. 43.

53. A. Ivars, "Orige i significació del "drach alat" i del " rat penat" en les insignies de la ciutat de Valencia », III Congreso de historia de la Corona de Aragón. Valence, 1923, t. II, pp. 49-112.

54. H. LeE, M. E. ReEves, G. Silano, Western..., op. cit., pp. 8-13. 
par un ange à un moine qui célébrait la messe sur le mont Carmel ; ce carme envoya le texte miraculeux à son ami Joachim de Flore qui le rendit public. Dans cet opuscule, le grand dragon (lire Pierre III) et son ennemi le lion féroce (Charles Ir d'Anjou) décident d'engager un duel (à Bordeaux, en 1283); le petit du lion (Charles II) est capturé ensuite sur un navire (dans la bataille au large de Naples, le 5 juin 1284) ; les «draconites » le détiennent pour qu'il lèche leurs plaies (sa captivité en Catalogne), mais la Vierge (l'Eglise) obtient sa libération (en octobre 1288). La métaphore reptilienne du dragon est ici, en apparence, très péjorative à l'endroit de Pierre III. Pourtant, l'Oracle de Cyrille connaît un large succès en Catalogne, où - à en croire la sentence inquisitoriale de 1316 - Arnaud de Villeneuve et ses disciples lui accordaient, en tant qu'Évangile éternel du troisième âge, un crédit supérieur aux Ancien et Nouveau Testaments révolus. Vers 1380, une prophétie catalane favorable à Urbain VI (13781389) affirme que cet oracle "vaut plus que la moitié de la Bible »55. Au $14^{\mathrm{e}}$ siècle, l'Oracle de Cyrille est devenu le plus populaire des libelles pseudo-joachimites circulant dans la Couronne d'Aragon.

Autour de 1345-1349, Jean de Roquetaillade reprend, dans son Commentaire à l'oracle de Cyrille, le thème du dragon, métamorphosé parfois en scorpion, issu de la race néfaste de Frédéric II et échoué en Sicile, en lutte contre les Angevins français, dont l'image inverse sont le soleil, vainqueur des ténèbres, et le lion courageux ${ }^{56}$. Dans le Livre des secrets ${ }^{57}$, il présente le grand dragon rouge qui s'envole pour persécuter la femme. Or, les idées de Roquetaillade sont largement diffusées dans les milieux franciscains proches du roi d'Aragon.

Après la maison de Barcelone, les Trastamare s'emparent de la figure apocalyptique du saurien. Le pseudo-Arnaud de Villeneuve affirme que « la sixième tête du dragon, dont il est question dans le Nouveau Testament, descend de la génération et de la semence du roi Pierre d'Aragon ${ }^{58}$. Rédigée en 1449 par un religieux anonyme, une prophétie catalane prédit les victoires eschatologiques que remportera, sous peu, le roi d'Aragon, "Drach onzè » : cette allusion renvoie à la onzième corne poussant à la quatrième bête de la vision de Daniel VII, figure d'un roi qui en écrasera trois autres ${ }^{59}$. Dans le Breviloquium (1351-1354) d'un béguin catalan, Pierre IV, onzième roi, apparaissait déjà comme la dernière corne de cette bête terrifiante. En somme, l'Oracle de Cyrille, son commentaire par Jean

55. P. Bohigas, «Profecies catalanes... », art. cité, p. 34, n"14-15.

56. Cf. le travail excellent de M. Bollloux, Étude d'un commentaire prophétique du XIV" siècle: Jean de Roquetaillade et l'Oracle de Cyrille (v. 1345-1349), thèse inédite de l'École des chartes, Paris, 1993, pp. 35-36, 49-51, 139-148, 158-159.

57. En attendant l'imminente parution de son édition par C. Morerod-Fattebert et R. Lerner dans la collection "Spicilegium Friburgense ", l'on se reportera à J. BigNami-OdIER, "Jean de Roquetaillade... », art. cité, pp. 124 et 228.

58. BC, ms 490 , f. $100 \mathrm{v}$.

59. M. Acritl, «La fin du monde, l'enfer et le roi : une prophétie catalane du XV" siècle », Revue Mabillon, 1994, p. 153, 161, 166. 


\section{RITES, MÉMOIRE ET PROPHÉTIES}

de Roquetaillade et les prophéties catalanes sur les Trastamare confirment la dimension apocalyptique du cimier des rois d'Aragon.

Le dragon ailé que les rois portent sur leur casque prête parfois à confusion avec la chauve-souris. En 1356, Jean de Roquetaillade écrit, dans sa geôle avignonnaise, que l'infant Ferdinand d'Aragon, demi-frère de Pierre IV, porte un cimier en forme de chauve-souris : ce renseignement que lui ont fourni les cardinaux de la curie traduit peut-être une erreur largement répandue ${ }^{60}$. Sa méprise est d'autant plus excusable que, comme le fait remarquer Dionís Guiot dans le poème adressé en 1453 à Alphonse V, les ailes du dragon volant de son heaume sont bien celles de la chauvesouris ${ }^{61}$. Instrument de la propagande de la maison de Barcelone, ce quiproquo n'est pas tout à fait innocent.

L'oracle Vae mundo in centum annis! (Malheur au monde dans cent ans !), est rapporté pour la première fois en 1301 dans le De mysterio cymbalorum Ecclesie d'Arnaud de Villeneuve ${ }^{62}$. Il mentionne une chauvesouris qui dévore les moustiques (c'est-à-dire les Sarrasins) d'Espagne, soumet l'Afrique, humilie les habitants du Nil et instaure, après avoir broyé la tête de la bête, une monarchie universelle ${ }^{63}$. Cette prophétie se diffuse largement en Catalogne et au-delà ${ }^{64}$. Jean de Roquetaillade, qui y consacre un commentaire complet dans son De oneribus orbis (1354), la cite dans presque tous ses autres ouvrages ${ }^{65}$ : il personnifie la chauve-souris en l'infant Ferdinand d'Aragon, qu'il pense devoir supplanter Pierre $I^{\text {er }}$ sur le trône de Castille. Par contre, d'après le Primer del Chrestià (1379-1381) de Francesc Eiximenis, fidèle serviteur de la maison de Barcelone, « un grand docteur affirme que la chauve-souris veut dire le roi d'Aragon pour beaucoup de raisons qu'il serait long d'exposer ici. Il dit, de plus, qu'il doit soumettre l'Afrique, habitée aujourd'hui par les Sarrasins, et humilier la bête, à savoir prendre la Mecque où est enterré Mahomet, la grande bête, tête des Sarrasins, ainsi que le sultan de Babylone, tête des Maures ; finalement, il accédera

60. Fernandus super galeam vespertilionem gerit insigne armorum et tunc clarum esset quod ille, ex patre Aragonensi et ex matre Castellana, esset vespertilio destructor sarracenorum, cité dans M. Aurél.l, «Prophétisme et messianisme... », p. 353, n. 116.

61. Vi star un rey, portant sobre.l cap timbre: / vibra respant, de rat-penat les ales, cité dans M. de RiQuer, Heràldica catalana des de l'any 1150 al 1550, Barcelone, 1983, t. I, p. 24.

62. J. Perarnau, «El text primitiu del De Mysterio cymbalorum ecclesie d'Arnau de Vilanova. En apèndix, el seu Tractatus de tempore adventus Antichristi », Arxiu de textos catalans antics, 1988-1989, pp. 7-169.

63. Alain Milhou décèle, dans le terme latin vespertilio qui désigne ici ce chiroptère, un emprunt au vesper occidentalis, dérivé du hesperos grec, l'étoile du soir des prophéties byzantines et musulmanes des années 1200, annonçant l'avènement imminent d'un roi blond d'Occident à Constantinople, en Égypte et en Terre sainte, « La chauve-souris, le nouveau David et le roi caché ", Mélanges de la Casa de Velazquez, 1982, p. 65.

64. Il est encore copié, en 1494, alors que Charles VIII descend I'Italie pour reprendre Naples au roi d'Aragon, par un grammairien toscan, R. RuSCONI, " Ex quodam antiquissimo libello". La tradizione manoscritta delle profezie nell'Italia tardomedioevale », The Use and Abuse..., op. cit., pp. 446-447.

65. J. Bignami-Odier, «Jean de... », art. cité, pp. 134-141. 
à la dignité impériale ${ }^{66}$. Tandis qu'il prépare une campagne sarde, Jean $\mathrm{I}^{\mathrm{er}}$ est chanté comme suit dans une ballade française composée à sa cour : «Avis m'estoit qu'un fort vespertilon [chauve-souris] / en conqueste surmontait Alixçandre. / Mais Seril [Cyrille] montre en sa vray description / que c'est le roy qui tient en compagnye ${ }^{67}$. Le prestige du roi symbolisé par la chauve-souris, destructeur de l'Islam et promis à l'empire universel, est immense.

C'est la raison pour laquelle les Trastamare essaient d'obtenir l'attribution des figures prophétiques du Vae mundo, traduit du castillan depuis au moins $1344^{68}$, à leur personne. A l'époque où ils arrachent la couronne au roi de Castille, l'infant Pierre d'Aragon, franciscain depuis 1358, affirme qu'Henri II est la chauve-souris, bientôt victorieuse de Pierre ${ }^{\text {er }}$ présenté sous les traits de la planète malfaisante de Saturne ${ }^{69}$; le caractère partisan de son commentaire s'explique par le fait que, peu avant son entrée dans l'ordre des mineurs, l'infant Pierre, sénéchal de Catalogne, avait commandé les troupes aragonaises qui appuyaient, à la frontière de Valence, la révolte des Trastamare.

Devenus rois d'Aragon, les Trastamare sont régulièrement désignés, dans les vaticinations catalanes du $15^{\mathrm{e}}$ siècle, par le qualificatif de vespertilio : c'est particulièrement vrai autour de 1453, date de la chute de Constantinople que le pape aimerait voir libérée par une croisade menée par Alphonse $\mathrm{V}^{71}$. La prophétie anonyme de 1449 parle indifféremment de ce roi comme du onzième dragon ou de la onzième chauve-souris, tandis que l'oracle valencien Surge, vespertilio, surge! l'encourage à combattre le Turc ${ }^{71}$. Mais c'est en l'honneur de Ferdinand le Catholique, libérateur de Grenade, que cette métaphore, liée à la reconquête définitive de l'Espagne, est le plus employée.

Le dragon volant et la chauve-souris apparaissent en somme comme des emblèmes de guerre. Le premier est plus spécifiquement utilisé contre les Angevins de Naples, soutenus par la papauté, alors que le second combat les musulmans, insectes engloutis par le chiroptère. Plus justifiable sur le plan idéologique, l'emploi de la chauve-souris finit par s'imposer, tout particulièrement sous le règne de Ferdinand le Catholique, le roi qui mène à bout la Reconquête. A l'époque moderne, la chauve-souris remplace même, dans les armes de Valence, le dragon ailé devenu trop encombrant, en raison de ses connotations maléfiques. Il n'en reste pas moins que, des

66. P. Bohlgas, «Prediccions i profecies en les obres de Fra Francesc Eiximenis », Franciscalia, Barcelone, 1928, p. 29.

67. W. APEI, French Secular Music of the Late Fourteenth Centun;, Cambridge, Ma., 1950, pp. 31 et $71-72, n^{\circ} 44$.

68. A. IVARS, « Orige i significació... », art. cité, PJ IV.

69. R. E. LiRner, The Powers of Prophecy. The Cedar of Lebanon vision from the Mongol Onslaught to the Enlightenment, Berkeley, 1983, pp. 141-144.

70. S. Sobrequìs, «Sobre el ideal de cruzada en Alfonso V de Aragón », Hispania, 1952, pp. 232-252.

71. M. Atrhtl., «La fin du monde... », art. cité, pp. 161 et 166 ; A. IVARS, " orige i significació.... ", art. cité, PJ X. 


\section{RITES, MÉMOIRE ET PROPHÉTIES}

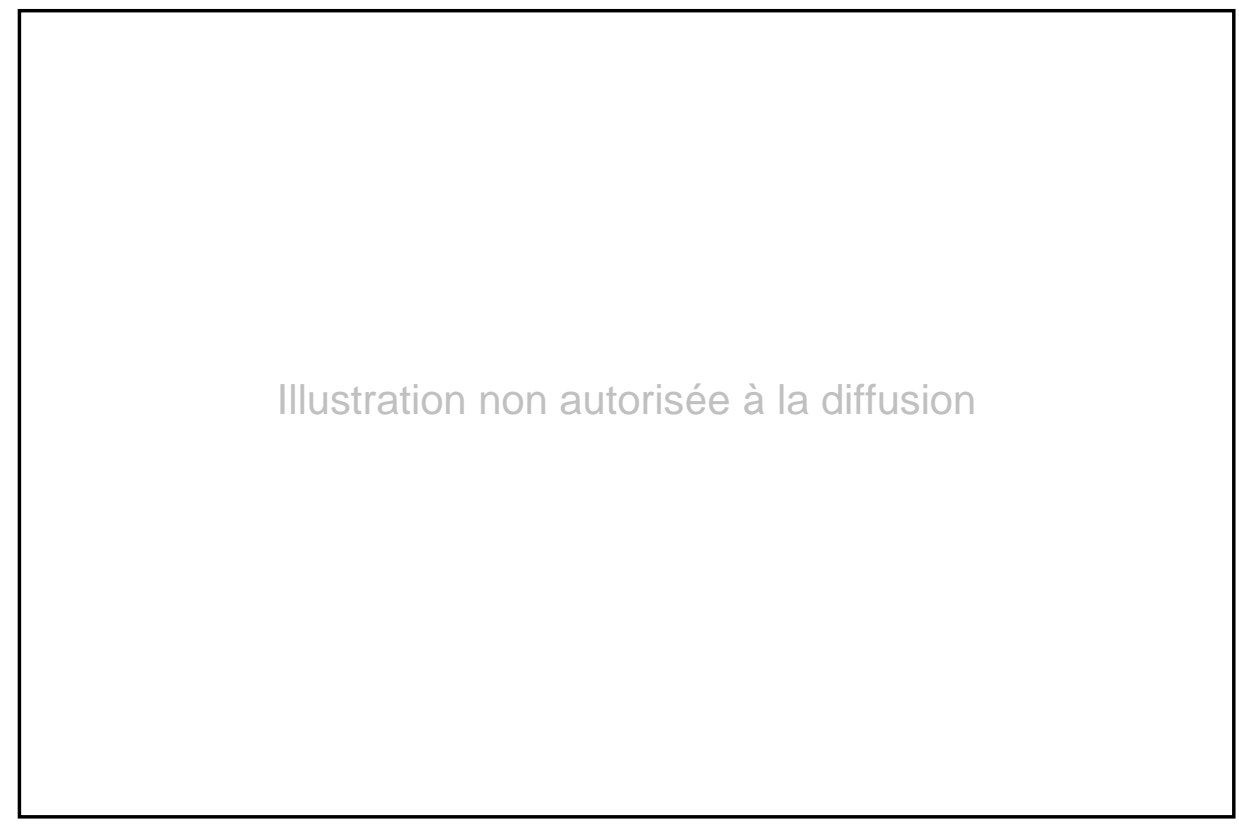

FIG. 4. - Petit quartier en ivoire de la selle à monter de Pierre III, représentant l'aigle impérial (Musée du Louvre, Paris)

siècles durant, c'est bien le dragon, monstre apocalyptique et terrifiant, hâtant la fin du monde, qui avait surplombé, du haut du casque des rois et des infants d'Aragon, leurs adversaires.

\section{De l'empire à la Catalogne : l'aigle impérial}

Figure héraldique des Hohenstaufen, l'aigle de sable est hérité par les rois de Sicile de la maison de Barcelone. Leur écu écartelé en croix de saint André le fait coexister avec les quatre pals de gueules catalans. En revanche, au $14^{\mathrm{e}}$ siècle, les rois d'Aragon ne l'introduisent pas encore dans leurs armoiries. Il n'empêche qu'ils s'en servent comme d'un motif ornemental chargé de signification (figure 4). Au $14^{\mathrm{e}}$ siècle, cette figure animalière, importée de l'Italie impériale, est devenue courante dans l'iconographie du palais royal de Barcelone ${ }^{72}$. Sous les Trastamare, le retour définitif de l'île à la Couronne d'Aragon augmente son utilisation : les deux aigles de la Sicile entrent désormais dans leurs armes. Au milieu du $15^{\mathrm{e}}$ siècle, l'humaniste Alphonse $\mathrm{V}$ aime particulièrement cet emblème romain ${ }^{73}$. Dans le sceau de Ferdinand le Catholique, l'aigle auréolée remplace l'ancien cimier au dragon ailé. Cette substitution s'est même opérée dans la vaticination urbaniste des années 1380: «L'aiglon sera conservé sous

72. M. de RiQuer, "Aspetti artistici e culturali », La società mediterranea all'epoca del Vespro, Palerme, 1983, t. I, pp. 129-141.

73. G. L. HERSEY, The Aragonese Arch at Naples, 1443-1475, New Haven, 1973, p. 28. 
le dragon; il lui succédera à la place de son père ${ }^{74}$. Comme le dragon volant ou la chauve-souris, l'aigle est une bête chargée d'un fort contenu eschatologique.

Composé vers 1420 , l'oracle du pseudo-Arnaud insiste sur la portée apocalyptique de cet aigle héraldique : «Le roi des Aragons est dit roi de l'orient et du nord (aquilonis), en raison des deux aigles qu'il porte dans ses armes pour le royaume de Sicile, qui se trouve à l'est. Il mettra le feu dans les lieux où son armée sera rassemblée, comme le dit Isaïe ${ }^{75}$. L'emploi de l'aigle des Hohenstaufen dans un contexte prophétique est bien plus précoce : Pierre de la Vigne avait, deux siècles auparavant, identifié son maître Frédéric II au « grand aigle » évoqué par le prophète Ézéchiel. Les pseudo-joachimites avaient ensuite utilisé cette métaphore à profusion : la sybille Érythrée proclamait qu'il n'y aurait d'autre empereur en dehors de la descendance de l'aigle ${ }^{76}$. Or, dès la fin du $13^{e}$ siècle, les Barcelonais apparaissaient, en Italie, comme les seuls héritiers des Hohenstaufen.

Salimbene d'Adam (1221-1288), franciscain de Parme, est le premier qui se fait l'écho de leur nouveau rôle messianique copiant dans sa chronique une longue prophétie qu'il attribue à la sybille. Il est question d'un aigle au dur visage (Pierre III) réclamant le royaume de Trinacrie (la Sicile), s'unissant à une poule orientale (Constance) et combattant le lion $\left(\text { Charles } \mathrm{I}^{\mathrm{er}}\right)^{77}$. Des prophéties semblables circulent, vers 1300, en Catalogne où Constance apparaît, plus logiquement, en tant qu'aiglonne. Le Breviloquium mentionne le mariage entre Pierre III, l'insigne corne du bouc, et Constance, l'unique petite de l'aigle: c'est dans leur descendance que surgira le onzième roi destructeur ${ }^{78}$. Le transfert de l'aigle des Souabes aux Barcelonais n'est pas seulement héraldique mais eschatologique.

Cette translation prophétique de la Sicile vers la Catalogne est souvent évoquée dans l'œuvre de Jean de Roquetaillade. Dans le Livre révélateur, le franciscain auvergnat attribue à Merlin une prophétie répertoriée en Aragon en 1285, au moment où Philippe III battait en retraite de sa croisade catalane. Cet oracle mentionne un aigle ardent, surgi de la terre, qui mouille la poitrine du plus grand avec le liquide virginal qui jaillit de son ventre. Pour Roquetaillade, ce rapace est un futur empereur romain, furieux et coléreux, qui verse le sang du souverain pontife ; la terre humide dont il provient n'est autre que la Sicile. La conclusion s'impose donc: «Je crois, comme beaucoup, que cet aigle monte des humeurs du roi Pierre d'Aragon et de sa race ». Pour ce franciscain, admirateur de la maison de Naples, l'aigle exécrable incarné par les Catalans de Sicile est la seconde tête d'Apocalypse XIII, antéchrist séduisant et thaumaturge amenant l'humanité à la perdition.

74. P. Bohigas, "Profecies catalanes... ", art. cité, pp. 34-35, n" 15.

75. BC, ms 490, f. $101 \mathrm{v}$.

76. M. E. REFVES, The Influence of Prophecy in the Later Middle Ages, Oxford, 1969, p. 310.

77. G. SCALIA éd., Bari, 1966, pp. 794-796.

78. P. Bohigas, "Profecies catalanes...", art. cité, p. 25, n"1; H. LeE, M. E. Reeves, G. Sil_ANO, Western..., op. cit., pp. 206 et 245. 


\section{RITES, MÉMOIRE ET PROPHÉTIES}

La prophétie anonyme de 1449 est, par contre, favorable à Alphonse V, le roi qui arrache Naples aux Angevins. Sous sa dictée, l'aigle du roi de Sicile est devenu l'ange puissant et bienheureux de Dieu d'Apocalypse X, posant son pied droit sur la mer et son pied gauche sur la terre, double symbole de ses victoires, aussi bien navales que terrestres ${ }^{79}$. Malfaisant pour les uns, bienfaisant pour les autres, l'aigle des Hohenstaufen, figure héraldique progressivement récupérée par les rois d'Aragon, ne traduit pas moins une vocation messianique aux yeux des Français comme des Catalans.

Célébré en 1262, le mariage entre Pierre III et Constance, associant la maison d'Aragon à la destinée apocalyptique des Hohenstaufen, est central dans ces oracles. Grâce à cette union, les Barcelonais s'approprient les attributs messianiques de Frédéric II. Ils deviennent la race maudite des gibelins, élément central du système eschatologique des pseudo-joachimites de la fin du $13^{\mathrm{e}}$ siècle. Dans la littérature prophétique, le souvenir de ces épousailles franchit aisément le cap des années 1300. Parce qu'elle a lancé l'expansion catalane en Méditerranée orientale, cette union matrimoniale, jetant les bases du messianisme des princes de la maison de Barcelone, descendants uniques de Frédéric II et ennemis de la papauté, attire l'attention de nos visionnaires. Facile à assimiler au bestiaire apocalyptique, effrayant, belliqueux et destructeur, l'aigle des Hohenstaufen, que les rois d'Aragon incarnent par le sang de leur aïeule, l'aiglonne Constance, est largement employé dans leur emblématique.

\section{De l'Aragon à la Castille: Pierre, Alphonse et les autres}

Les textes prophétiques catalans consacrent quelques développements aux noms des monarques dont ils essaient de percer les mystères à l'aide de l'étymologie, de l'acrostiche et de la numérologie, méthodes classiques d'interprétation onomastique, dans lesquelles on peut également déceler de vagues influences de la kabbale languedocienne ${ }^{80}$. A partir des noms, chargés d'une signification ésotérique, ces oracles percent les mystères d'un avenir tout proche, proposant une interprétation eschatologique et une destinée universelle aux monarques des maisons de Barcelone et de Trastamare.

Pierre, nom de la dynastie aragonaise introduit dans la maison de Barcelone vers 1160 , évoque le roc. Deux prophéties du début du $14^{\mathrm{c}}$ siècle parlent d'un roi à qui la pierre de Constance donne son nom. Pierre III est encore étroitement lié à l'héritière de Sicile qui porte au féminin le nom impérial par excellence, faisant, déjà au $4^{c}$ siècle, l'objet d'un traitement messianique par un texte sibyllin, où un empereur appelé Constantin convertit les juifs, anéantit Gog et Magog, conquiert Jérusalem, dépose sa couronne

79. M. Aurfi. ., « Prophétie et messianisme... », art. cité, p. 328 ; « La fin du monde... », art. cité, pp. 1.53 et 161 .

80. Arnaud de Villeneuve, père du prophétisme catalan, étudie et enseigne la médecine à Montpellier dont est issue sa femme Agnès Blasi. Une importante communauté juive, très active sur le plan intellectuel, demeure dans cette ville. Or, Arnaud est l'auteur, en 1292, d'une Allocutio super significationem nominis Tetragrammaton, au titre et à la méthode significatifs de ces influences, J. Carreras éd., Sefarad, 1949, pp. 75-105. 
sur le Golgotha et monte vers Dieu. Pour l'auteur du Breviloquium en revanche, Pierre, nom du premier pape, sera aussi celui du dernier destructeur : "Pierre commença et Pierre amènera la fin! Le onzième roi : sang, sédition, mort et ruine ». Ces malheurs seront provoqués en 1367 par Pierre IV d'Aragon, dont le nom dévoilera, de la sorte, tout son sens caché ${ }^{81}$.

Conservée dans un manuscrit catalan du $15^{\mathrm{e}}$ siècle, une lettre en vers, très populaire en Italie, qu'on prétendait envoyée par Frédéric II au pape Innocent IV, décortique en quatre syllabes (Fre-de-ri-cus) le nom de l'empereur, associant chacune d'entre elles à une métaphore : " fré-missement » du monde, «dé-pression » des hauts dans les profondeurs, "ri-me » avec fauve et "cus-pis» ou lance ${ }^{82}$. Pour son couronnement, Ruggerio da Lauria, le grand amiral, prononça un discours lui exposant les trois raisons pour lesquelles il était «le troisième Frédéric dont les prophètes disaient qu'il deviendrait le roi de l'empire et de la plupart du monde » : il apparaissait, en effet, comme le troisième fils de Pierre III, le troisième Frédéric à régner sur la Sicile et le troisième Frédéric qui serait élu empereur d'Allemagne ${ }^{83}$. Ce roi de Sicile prenait alors conscience de tout le prestige que lui accordait son nom, celui de son aïeul mythique, dont le retour était tant attendu en sa propre personne. Ces élucubrations accompagnaient son évangélisme militant et son joachimisme.

En 1342, Louis montait sur le trône de Frédéric III, son grand-père. Son nom, hérité de la dynastie de sa grand-mère, Aliénor d'Anjou, était des plus capétiens. En 1349, Jean de Roquetaillade, dévot des deux saints Louis de cette maison, parvint - par le biais d'une anecdote qu'il disait avoir entendue d'un prêtre habitant en Sicile - à justifier cette dénomination, aberrante à son goût, d'un prince qu'il tenait pour l'antéchrist lui-même. Les garçons de Pierre (1337-1342), roi de Trinacrie, mourraient tous en bas âge; son épouse convoqua les sages-femmes de la cour pour leur soumettre ce problème; l'une d'entre elles lui proposa les services d'une sorcière qui habitait dans l'île ; cette femme lui conseilla de baptiser son prochain fils du nom de Louis pour assurer sa survie; la reine répondit qu'elle n'y parviendrait jamais, en raison de son mari, qui tenait ce prénom pour détestable à cause des Français ; elle réussit cependant à le convaincre ; Louis, l'enfant né dans ces circonstances mystérieuses, succéda peu après à son père. L'inspiration de ce nom, continue Roquetaillade, était bien démoniaque : l'addition de ses lettres - $\mathrm{L}+\mathrm{V}+\mathrm{D}(\mathrm{O})+\mathrm{V}+\mathrm{I}+\mathrm{C}+\mathrm{V}(\mathrm{S})$ - donne le chiffre 666 qui, d'après la prophétie d'Apocalypse XIII, est celui de l'antéchrist. L'action anti-pontificale de Louis de Bavière et de son antipape ne témoignait-elle pas, de façon prémonitoire, de l'hostilité d'un

81. P. Bohigas, "Profecies catalanes...", pp. 25 et 48 , n" 1 et 41 ; M. E. Reeves, The Influence..., op. cit., p. 299 ; H. LEE, M. E. REEVE.S, G. SII.ANO, Western..., op. cit., p. 317.

82. P. Bohigas, «Profecies de Merlí... », art. cité, p. 256. La nuance eschatologique en moins, ces vers rappellent l'étymologie qu'un troubadour anonyme proposait à l'adresse du jeune Frédéric III, amateur de pauvreté spirituelle : "Frédéric veut dire "Frein des riches" ". V. de Bartholomaeis, Poesie Provenzali Storiche relative all'Italia, Rome, 1931, n"184, vers $31-32$.

83. Ramon Muntaner, Cromica, F. Soldevila éd.. Barcelone, 1971. p. 833. \$ 185. 


\section{RITES, MÉMOIRE ET PROPHÉTIES}

empereur portant ce nom contre l'Église ${ }^{8+}$ ? Le franciscain auvergnat fut bien déçu en 1355, année de la mort de Louis de Trinacrie, qui n'avait pu jouer le rôle eschatologique qu'il lui avait prophétisé.

Les oracles catalans du $15^{\mathrm{e}}$ siècle s'étendent sur les noms castillans d'Alphonse et de Ferdinand, portés par les Trastamare. Vers 1420 , le pseudo-Arnaud rapporte deux étymologies latines promises à un long avenir: d'une part, Alphonse veut dire celui qui monte en fumée ou au sommet, à savoir à la dignité impériale ; d'autre part, Ferdinand est « la forge du fer ${ }^{85}$. Ce dernier nom est porté par le fils naturel d'Alphonse V, devenu, à sa place, roi de Naples entre 1458 et 1494 : sa naissance illégitime le prédispose à assumer les fonctions de l'antéchrist, un bâtard d'après la croyance commune ${ }^{86}$. Écrit vers 1470 , le dialogue prophétique entre le tertiaire Joan de Bur et l'ermite égyptien Tadeu rend un sens certes positif à l'action de Ferdinand le Catholique, «chauve-souris de votre Espagne et étincelle de feu occidental dont beaucoup ont parlé ». Mais le roi, dans toute l'ambiguïté du personnage de l'ange exterminateur, demeure l'antéchrist mystique ou mixte, précurseur royal, à la suite d'Olieu, du vrai antéchrist: "Son nom sera métal mixte (mistich) de fer allié avec de l'or, argent, plomb, étain et cuivre ${ }^{87}$. Cette métaphore ne va pas sans rappeler le savoir alchimique de l'antéchrist, capable de transformer les métaux en or, achetant les hommes corrompus par cette même cupidité que combattent, par leur dénuement, les franciscains observants. Liées à la fumée, au feu et au creuset, les interprétations du nom d'Alphonse et de Ferdinand évoquent une destruction terrifiante, infernale.

Aux $14^{\mathrm{e}}$ et $15^{\mathrm{e}}$ siècles, la symbologie politique catalane présente un bien effroyable visage. Les rois d'Aragon puisent leur emblèmes dans les plus redoutables bêtes de l'Apocalypse : sauriens, chiroptères et rapaces surplombent leur heaume et occupent même le champ de leurs armes. Reprises, paradoxalement, dans des textes joachimites hostiles à leurs ancêtres, ces figures plutôt répugnantes ont perdu une partie de leur signification nuisible. Terrifiantes, elles naissent dans un monde ravagé par la guerre et apportent à leurs détenteurs un lustre militaire des plus prestigieux. Ces bêtes sur-

84. Ce passage du Livre des secrets a été publié par J. Bignami-Odier ( Jean de Roquetaillade... », art. cité, pp. 132-133), qui identifie, par mégarde, les parents de Louis de Trinacrie à Pierre III et Constance de Hohenstaufen, au lieu de Pierre (1337-1342) et sa femme Isabelle de Carinthie.

85. Nomine hujus erit de forga ferri [...]. Alfonsus qui, in tempore, ascensor in fumum alias in sumum et ad imperium assendens, BC, ms 490, f. 100 v.-101 r.; axi com lo nom del molt alt senyor denota, qui es dit Alfonsus, muntador en fum. M. Aurell., « La fin du monde... », p. 167.

86. Lo qual es lo fill del dit senyor [Alphonse V], qui sera son nom per forge de ferro, ço es ferro ferrando, qui es antecrist mistich, ibid., p. 161.

87. Biblioteca de la Universitat de Barcelona, ms 82, f. 6 v., prophétie indiquée par P. Bohigas, «Profecies catalanes... », art. cité, p. 43, n" 33, qui l'attribue au règne d'Alphonse $V$ († 1458), alors que l'allusion de l'union des couronnes d'Aragon et de Castille en un seul roi qui épouse une infante nous semble, plutôt qu'une prédiction politique, une constatation $a$ posteriori, déguisée en vaticination, du mariage de Ferdinand et Isabelle, contracté en 1469. Les oracles sur Ferreus, trop mélioratifs, renvoient à Ferdinand le Catholique et non pas à Ferdinand, roi de Naples, peu populaire en Catalogne. 
humaines symbolisent l'antéchrist mystique, Empereur des derniers temps écrasant sans merci ses ennemis et imposant impitoyablement sa domination universelle. Pour celui qui sait déceler le sens caché des mots et lire les signes avant-coureurs de la fin des temps, son nom recèle le feu et la fumée, la plus terrible et dévastatrice des armes. Engagés dans un discours de la destruction, nos prophètes anonymes forgent une idéologie de combat fondée sur le rejet de l'autre.

\section{Un refus identitaire : séculiers, Français et Sarrasins}

Dans son commentaire à la prophétie Cedrus alta Libani, l'infant Pierre trouve l'étymologie d'Aragon dans l'expression «ara agonis, qui veut dire autel de bataille, où les idolâtres sacrifiaient à Mars, dieu de la guerre »; il ajoute que cette divinité païenne a donné son nom à la planète que les astronomes identifient avec Pierre IV. A la même époque, le Breviloquium indique que le terme Catalogne vient de "Logos qui veut dire "parole" et de cathalicio qui veut dire "dévastation" ${ }^{8 x}$.

Le goût pour l'étymologie belliqueuse n'est pas spécifique à la maison de Barcelone, au cours d'une période où, de ce côté-ci des Pyrénées, la filiation du nom de la France est cherchée, non pas tant dans des notions de franchises et de liberté, comme par le passé, mais dans des radicaux, repris à la chronique mérovingienne de Frédégaire, évoquant la barbarie ou la férocité ${ }^{89}$. La guerre de Cent Ans en-deçà de cette chaîne et l'impérialisme méditerranéen au-delà font converger, dans un seul et unique mensonge, la découverte de l'étymologie nationale sur un champ sémantique qui est celui de l'extermination. L'exacerbation militaire autour d'un roi se concrétise dans le refus de l'autre, dont il faut effacer par les armes toute trace de la surface de la terre.

Les élucubrations sur le mot qui désigne le royaume ou la principauté territoriale coïncident, assurément, avec la naissance d'un sentiment national. Ce patriotisme embryonnaire traduit une identité, la conscience d'appartenir à un groupe cohérent, dont nos prophètes adoptent les finalités politiques, les valeurs communes et les marqueurs emblématiques. Cette identité positive, défensive, prend un visage plus agressif, négatif et offensif quand elle se définit par opposition à d'autres catégories dont l'altérité est fortement rejetée. L'Eglise romaine, la royauté française et les musulmans, ennemis de la maison de Barcelone, deviennent des pôles répulsifs dans les oracles catalans.

\section{Contre l'Église charnelle et ses richesses}

A l'orée du $14^{e}$ siècle, la figure de Frédéric III, en lutte contre la papauté contestant sa domination sur la Sicile, éveille un espoir messianique chez

88. A. M. de BARCELONA, «El infante fray pedro de Aragón ", Estudios franciscanos, 1915 , pp. 62-63 ; H. LFE, M. E. Rei:ves, G. Silano, Western..., op. cit., p. 207.

89. C. Beaune, Naissance..., op. cit., p. 312. 


\section{RITES, MÉMOIRE ET PROPHÉTIES}

les hérétiques exclus de la chrétienté. L'inquisiteur Bernard Gui mentionne la croyance des spirituels à la destruction prochaine de l'Église romaine ou charnelle par ses troupes. Il analyse les lettres rédigées en 1300 et en 1303 par Dolcino de Novare, chef des apostoliques : elles prophétisent l'action eschatologique de Frédéric III qui passera au glaive le pape, les cardinaux, les clercs, les moines, les nonnes et les autres religieux. Loin de l'Italie, au cœur des Pyrénées, Bélibaste, le dernier des cathares, se fait l'écho de ces idées, se réjouissant d'avance de voir fouler l'Église démoniaque par le roi de Trinacrie ${ }^{90}$.

Pour ces hétérodoxes, imbus d'évangélisme, Frédéric III doit écraser Boniface VIII, responsable de la démission de Célestin V, le très saint pape spirituel. Son combat prépare l'avènement du millenium qui, sous la conduite d'une Église charismatique, apportera mille ans de bonheur aux hommes, libérés de toute contrainte cléricale ou seigneuriale. Le souvenir de Frédéric III se perpétue en Catalogne : rédigée en 1469 en l'honneur de Ferdinand le Catholique, une prophétie latine conservée à Vic loue l'action de son ancêtre sicilien qui corrigea le pape et les clercs, les dépouillant de leurs luxueuses richesses et de leur vaine puissance ${ }^{91}$.

Tout au long des $14^{\mathrm{e}}$ et $15^{\mathrm{e}}$ siècles, l'image d'un prince dont la persécution régénère l'Église, plutôt qu'elle l'affaiblit, est appliquée au roi d'Aragon. Francesc Eiximenis contribue largement à sa diffusion. Daté de 13781380, son De Triplici statu mundi, au titre joachimite des plus significatifs, vaticine l'avènement d'un antéchrist mixte, à savoir un monarque issu de la maison de Barcelone s'attaquant à l'Église charnelle et aux clercs mondains ${ }^{12}$. A lire ce franciscain, les armoiries du roi, aux quatre pals de gueules sur champ d'or, symbolisent les châtiments dont il doit punir les clercs indignes: " De grands astrologues et théologiens, oints d'esprit de prophétie, disent que ces longues barres rouges et jaunes signifient les bâtons, les coups et les persécutions qui doivent sortir de la maison d'Aragon contre les mauvais ecclésiastiques pour purger leurs péchés, pour abaisser leur orgueil et leur pompe et pour les réduire à leur état originel [...]. Le champ de ces armes est jaune et ses pals sont rouges: cela veut dire que Dieu Notre Seigneur frappera, avec les bâtons de cette maison, l'or de la dignité ecclésiastique et que toute l'Église sera rendue rouge par l'effusion du sang ${ }^{93}$. Justifiant le patronage princier sur les institutions ecclésiales, l'association de l'écu du roi d'Aragon à la réforme violente de l'Église est promise à un long avenir. Elle devient un topos que reprennent quelques oracles consacrés aux Trastamare ${ }^{94}$.

90. Bernard Gui, Manuel de l'inquisiteur, G. Moli.at éd., Paris, 1926, t. I, pp. 144-145, t. II, pp. 87-101 ; E. Le RoY LADURIE, Montaillou, village occitan, Paris, 1975, p. 523.

91. A. Grit:RA, "Una profecia», Butlletí del centre excursionista de Vich, 1912-1914, pp. 154-155.

92. A. G. HaUf, «El De triplici statu mundi de Fr. Francesc Eiximenis, o. f. m. », Estudis universitaris catalans, 1979, p. 277. Cf. J. Perarnal, "Documents i precisions entorn de Francesc Eiximenis (c. 1330-1409) », Arxiu de Textos Catalans Antics, 1982, p. 200.

93. P. Bohigas, "Prediccions... », art. cité, p. 30.

94. Baculi seu virge rubee super nova stanza Ecclesie fraet et percusiet ipsas ecclesias, $\mathrm{BC}, \mathrm{ms} 490, \mathrm{f} . ;$ Les vergues del mots alt excellent senyor rey d'Arago, XI vespertilio, les 
Ce discours, hostile à l'Église, est emprunté à Joachim de Flore. Il se fonde sur l'idée du dépassement du second âge, temps des clercs séculiers et des ordres religieux traditionnels, bel et bien révolu. L'avenir appartient aux mineurs, tandis que la prédication sur la pauvreté de saint François, l'ange de l'Apocalypse brisant le sixième sceau, vient d'ouvrir le troisième âge définitif du Saint-Esprit. La joie d'Arnaud de Villeneuve apprenant la dissolution des Templiers traduit cette croyance en l'imminence de la disparition des religieux autres que mendiants.

C'est dans un contexte eschatologique que les spirituels joachimites blâment la richesse de l'Église tout entière. Une prophétie anonyme de 1370 s'en prend amèrement à Boniface VIII, bête apocalyptique, "maltraitant l'Église et tentant de détruire la pauvreté évangélique de la vie du Christ et des apôtres $\gg^{95}$. Jean XXII, hostile à la première règle franciscaine, est aussi détestable: Philippe de Majorque le traite d'antéchrist maxime, persécuteur de la vie et de la perfection évangélique et destructeur de la vérité du Christ. Pour les béguins roussillonnais, ses disciples, l'Église est devenue une nouvelle Babylone, grande prostituée, épouse répudiée par le Christ depuis qu'elle a versé le sang des martyrs spirituels persécutés par l'inquisition ${ }^{\%}$. Sous un jour plus nuancé, ces idées se retrouvent dans les œuvres des franciscains catalans du $14^{\circ}$ siècle qui croient à la progressive décadence du clergé, en attendant une purification eschatologique.

Ces opinions ne laissent pas la royauté indifférente. Le modèle spirituel détermine la figure et la piété du monarque : une prophétie confectionnée en Catalogne vers 1300 parle de Pierre III comme du « roi pauvre sorti de l'Espagne ${ }^{97}$; ses enfants Frédéric III et Jacques II cultivent la pauvreté évangélique. Mais cette attitude ne semble pas exempte d'arrière-pensées politiques à l'époque où le conflit entre le roi et la hiérarchie ecclésiastique éclate au grand jour. L'hostilité du Saint-Siège à l'implantation des Catalans en Sicile ne peut que pousser leurs partisans dans le camp de tous ceux qui protestent contre l'engagement trop intense des clercs dans les affaires temporelles. L'Église apparaît comme un contre-pouvoir, entravant le renforcement de l'État, qui s'intéresse de près aux ressources de sa fiscalité : Pierre IV occupe périodiquement les biens de la chambre apostolique ou réquisitionne les bénéfices des ecclésiastiques absents de son règne. Il proteste contre la nomination de l'archevêque de Saragosse par Clément VI, qui n'a pas daigné le consulter au préalable; il s'en prend à la papauté qui n'accorde pas de cardinalat aux prélats de ses principautés ${ }^{98}$. Le dévelop-

quals molt fort o agrament, gitaran foch e flama, batent-se ella, exint impietats d'aquells e cessara consell dels grans prelats e la ley dels sacerdots, M. AurFi. ., "La fin du monde... ", p. 161 ; e ab verga e basto e hauran innumerables persequtions e molts e grans inflictes de la sua ma e per aquest seran los ecclesiastichs oppresos e perseguits, Biblioteca de la Universitat de Barcelona, ms 82 , f. 8 v.

95. P. Bohigias, «Profecies de Merlí ... », art. cité, pp. 258-261.

96. J. M. Pou, Visionarios..., op. cit., pp. 176-180.

97. P. Bohigas, «Profecies catalanes... », art. cité, p. $25, n^{\prime \prime} 1$.

98. A. M. de Barchiona, «El infante...", art. cité, 1915, p. 217 ; R. d'Abadal, Pere el ceremoniós..., op. cit., pp. 148-149. 
pement de la monarchie et l'affirmation administrative des institutions ecclésiastiques sont incompatibles.

On comprend que Francesc Eiximenis ait perçu, à la cour de Pierre IV, les pals de l'écu catalan comme des verges destinées à battre le clergé, symbologie adaptée aux rapports tendus entre Barcelone et Rome. L'empereur Louis de Bavière, autre protecteur des spirituels, n'avait-il pas, quelques décennies auparavant, encouragé Marsile de Padoue et Jean de Jandun à développer l'averroïsme politique, philosophie enlevant à l'Église et au clergé toute intervention dans les affaires du siècle, pour les reléguer au seul domaine surnaturel ${ }^{99}$ ? Encore en 1527 , la justification d'un châtiment impérial de la papauté se trouve dans la lecture que les partisans de Charles Quint, descendant direct des rois d'Aragon, font du sac de Rome par les troupes ${ }^{100}$.

\section{Contre le roi de France et les Angevins de Naples}

Jean de Roquetaillade admire sincèrement les Angevins de Naples, issus de la noble maison de France, «mur d'airain » protégeant le Saint-Siège des agissements de la Sicile catalane. Sa méfiance est grande envers le roi d'Aragon: "Cette ambitieuse chauve-souris veut usurper le royaume de France, qu'elle frappera durement et couvrira de ruines, car la race de feu Pierre d'Aragon n'aime guère le prince gaulois, Empereur des Français ${ }^{101}$. Les Catalans ripostent par le mépris qu'ils affichent à l'égard de la maison rivale d'Anjou, qu'ils considèrent favorisée injustement par une papauté trop mêlée dans les affaires temporelles. C'est l'adversaire à abattre comme en témoigne la lettre qu'adresse Frédéric III, en 1296, à son frère Jacques II d'Aragon, se réjouissant à l'avance de la confusion finale et de l'anéantissement si désiré du peuple gaulois ${ }^{102}$.

Le prophétisme s'empare de cette lutte. Les pseudo-joachimites relatent le combat entre Charles d'Anjou, le lion féroce, et Pierre III, le dragon. Ces métaphores sont à ce point répandues qu'en 1293 Pandolfo di Falcono, porte-parole d'une ambassade sicilienne qui rejoint Jacques II à Lérida, le prie, dans un discours, de se ranger du côté de son frère dans la guerre où les coqs français prétendent dévorer les aiglons siciliens ${ }^{103}$. D'autres oracles insistent sur l'appui que le sanglier ou le renard anglais prêtera, dans ce combat, à l'aigle au détriment du coq ${ }^{104}$. Plus original, le Breviloquium voit une préfiguration de la lutte où s'affronteront Pierre IV et les Français dans

99. E. Gil.son, La philosophie au Moyen Age, Paris, 1944, pp. 687-694.

100. A. Chastel, Le sac de Rome, 1527, Paris, 1977, pp. 162-166, 192-197, 311.

101. J. Bignami-Orier, « Jean de Roquetaillade... », art. cité, pp. 140 et 199.

102. Finalem confusionem et stragem et precipue Gallicane gentis excidium, cuius extrema tandiu desiderata destruction vicina describitur, H. FINKE, Acta Aragonensia, Berlin-Leipzig, 1908 , p. 276 (13 mai 1296).

103. Bartholomal's de Neocastro, Historia Sicula, G. Carducci, V. Fiorino, éds, Rerum Italicarum Scriptores, t. XII (III), Bologne, 1921, p. 138.

104. P. BoHIGAS, "Profecies catalanes... », art. cité, p. 25, n'1; BC, ms 485, f. 262 r. Cf. C. Beaune, «Perceforêt et Merlin. Prophétie, littérature et rumeurs au début de la guerre de Cent Ans », Cahiers de Fanjeaux, 1992, pp. 237-256. 
la guerre qui opposa jadis Alexandre, aussi petit en taille que le roi d'Aragon, aux Mèdes de Darius ${ }^{105}$. C'est l'exception qui confirme la règle de l'utilisation par les prophètes des signes et des emblèmes héraldiques des maisons dont ils décrivent le conflit.

La familiarité avec ces thèmes explique en partie l'attitude de Bernard Delicios. Autour de 1300, ce franciscain spirituel se bat contre l'inquisition de Carcassonne. Afin d'en empêcher le fonctionnement et d'obtenir la libération de ses prisonniers, il fait appel à Philippe le Bel qui, loin d'écouter ses demandes, ordonne son arrestation. En 1304, quelques mois après la tentative de Bernard Saisset, évêque de Pamiers, de révolter les comtes de Foix et de Comminges contre la couronne, Delicios convainc les Carcassonnais d'abandonner le roi de France et de se donner un nouveau seigneur. Ce disciple de Pierre Jean-Olieu, prédicateur à la lumière de la sybille de la fin imminente du monde et lecteur assidu des Vaticinia de summis pontificibus, croit au messianisme de la maison d'Aragon, qui doit anéantir un jour la royauté française. Il se rend en Roussillon auprès du jeune Ferdinand de Majorque auquel il propose la domination sur Carcassonne. Mais le complot échoue: cinquante Carcassonnais sont pendus haut et court ${ }^{106}$. Leur démarche n'a pas moins connu la fascination pour les descendants de Pierre III et de Constance de Hohenstaufen, protagonistes de maintes prophéties.

Au $15^{\mathrm{e}}$ siècle, les oracles anti-français adoptent, en Catalogne, de nouveaux emblèmes pour désigner l'adversaire. La croix blanche de saint Michel, portée dans leurs habits par les soldats de l'armée royale de France à partir de 1355, symbolise l'ennemi dans les vaticinations favorables aux Trastamare: dans une prophétie faussement datée du 13 novembre 1415 , mais écrite sous Ferdinand le Catholique, cette croix est le signe du prince à qui Alphonse $\mathrm{V}$ arrache Naples; elle est accompagnée des fleurs de lis que frappent les neuf bâtons de la bannière du roi d'Aragon, qui flottera bientôt sur la ville de Marseille, allusion évidente au sac de cette ville en 1423.

Cet oracle mentionne également la grande bataille qui se déroulera entre Français et Aragonais sur la plaine de Salses ${ }^{107}$. Cette place forte du Roussillon, délimitant la frontière entre le royaume de France et la Catalogne, était de longue date devenue le lieu mythique d'un combat apocalyptique : la croyance d'une bataille de Salses au cours de laquelle les Sarrasins détruiraient l'Église charnelle apparaît dans un interrogatoire mené par Jacques Fournier en 1333 ; l'effusion de sang serait telle qu'il monterait jusqu'à la croupe des chevaux; de nombreux hommes ayant été tués dans

105. H. Lef, M. E. Reeves, G. Sal.ano, Western..., op. cit., p. 245.

106. J.-L. Biger, «Autour de Bernard Délicieux : franciscanisme et société en Languedoc entre 1295 et 1330», Revue d'Histoire de l'Église de France, 1984, pp. 79-93; P. M. de DMITREWSKI, "Frère Bernard Délicieux, o. f. m. », Archivum Franciscanum Historicum, 1924, pp. 327-333: A. CAZFNave, "Hérésic et société ». Heresis, 1989. pp. 32-33: H. Mill.et, D. Rigat:x, "Aux origines du succès des Vaticinia de summis pontificibus", Cahiers de Fanjeaux, 1992, pp. 136-138.

107. BC, ms 485 , f. 263 r.-v. et 265 v. 


\section{RITES, MÉMOIRE ET PROPHÉTIES}

ce combat, la polygynie se répandrait largement ${ }^{108}$. Dans la prophétie de 1449 , le thème du sang, qui coule entre Salses et le Val d'Aran, persiste mais les Catalans se battent désormais contre les peuples venus du nord ${ }^{109}$. Devenu un lieu d'affrontement obligé entre les troupes des rois d'Aragon et de France depuis la croisade anti-catalane de Philippe III, le Roussillon est le lieu où se fixe un imaginaire belliqueux.

A l'époque, le sentiment anti-français transparaît, de même, dans les dures critiques formulées à l'encontre de Yolande de Bar, nièce de Charles V, épousée en 1380 par Jean I ${ }^{\mathrm{er}}$ contre l'avis de son père qui voulait le marier à Marie, héritière de la Sicile. L'influence de la reine sur son mari était telle que sa belle-sœur Maria de Luna disait au sujet de Jean I $^{\text {er }}$ : "Il avait une femme française et il était tout français "110. Nos prophéties se font l'écho de ce mariage. Le pseudo-Arnaud de Villeneuve rappelle à Pierre IV, son interlocuteur imaginaire, qu'il avait été contracté contre son gré. Partisan des Trastamare, il s'en prend à Yolande pour avoir promu la candidature de Louis III d'Anjou, son petit-fils, au trône de l'Aragon. Seconde prostituée de l'Apocalypse, elle est responsable, par ses mauvais actes, de la fin de sa dynastie. Puisque Louis III n'a aucun droit sur Naples, Alphonse V conquerra cette ville : le léopard dévorera la fleur de lis ${ }^{111}$. Un mariage français ne peut, au cours d'une période où les Trastamare combattent les Anjou en Italie, qu'être mal perçu par les visionnaires de la cour de Barcelone.

Au service des factions, le joachimisme est devenu un élément de propagande dans le combat italien contre l'ennemi de toujours. Les figures et symboles empruntés aux armoiries deviennent les champions d'un duel dont l'issue acquiert une portée cosmique : le dragon, la chauve-souris et les pals se battent contre le lion, la croix blanche et la fleur de lis. C'est dans ces images que se fixe une conscience nationale primitive.

\section{Contre les musulmans et l'antéchrist oriental}

Francesc Eiximenis cite, dans son Llibre dels Angels (1392), une prophétie révélée à un évêque dans l'église du Mont-Saint-Michel, où il est question de l'extinction de la lignée des rois de France, châtiée par l'Angleterre; cet oracle enchaîne ensuite avec le combat victorieux que les royaumes d'Espagne mèneront contre l'Islam"' ${ }^{\prime \prime}$. Cette vaticination répond à une logique acceptée alors dans la confédération catalano-aragonaise, où le musulman est bien plus l'ennemi naturel que le Français, adversaire attitré des Anglais dans la guerre de Cent Ans.

La tradition prophétique relative à la lutte contre l'Islam est ancienne dans la péninsule Ibérique. Elle apparaît pour la première fois dans les

108. J. M. VIDAL, "Procès d'Adhémar de Mosset ", Revue d'Histoire de l'Église de France, 1910, p. 580.

109. M. Acrell, « La fin du monde... », art. cité, p. 168.

110. F. Soldevil.a, Història de Catalunya, Barcelone, 1963, p. 497.

111. BC. ms 490, f. $101 \mathrm{r}$.

112. P. Bohigas, "Prediccions... », art. cité, p. 34. 
chroniques asturiennes de la fin du $9^{\mathrm{e}}$ siècle qui plaignent la destruction de l'Espagne wisigothique, punie pour ses péchés par l'invasion arabe, et qui attendent avec espoir sa restauration future chez un descendant de la monarchie de Tolède. Ce schéma, fondé sur le binôme destruction/restauration, reste particulièrement vivace à la cour de Castille dont les rois se veulent les héritiers de leurs ancêtres wisigothiques. En revanche, cette idée est étrangère à la royauté catalano-aragonaise dont le messianisme, de nature exclusivement joachimite, est inexistant avant la conquête de la Sicile en $1282^{113}$. Tout au plus Jacques $I^{\text {er }}$ avait-il reçu, vers 1265 , le message d'un franciscain navarrais qui avait vu en rêve un ange lui annonçant qu'il devait restaurer la chrétienté en Espagne ${ }^{114}$. Cette appropriation par le comte de Barcelone de la Reconquista, de la récupération wisigothique des terres usurpées par les musulmans, est exceptionnelle.

Dans le joachimisme, le rôle du roi ibérique des derniers temps ne saurait se limiter simplement à l'expulsion des arabo-berbères de la péninsule. Ce prince, issu de la semence de Frédéric II, est l'antéchrist mystique des derniers temps, promis à la monarchie universelle. Il est la chauvesouris d'Arnaud de Villeneuve qui, après avoir dévoré les moustiques musulmans d'Espagne, conquiert l'Afrique tout entière. Il apparaît dans une prophétie attribuée à Merlin comme le lion hispanique qui rugit, après son couronnement, d'un rugissement qui s'entend jusqu'à Sion, qui dévore une innombrable multitude de païens et qui noie les mahométans ${ }^{115}$.

En 1356, Jean de Roquetaillade affirme, dans le Livre révélateur, que ce lion rugissant n'est autre que l'infant Ferdinand d'Aragon, demi-frère de Pierre IV. Il avance, de même, que l'antéchrist oriental, qui personnifie la secte musulmane, sera battu par l'antéchrist occidental qu'il identifie parfois au roi d'Aragon ${ }^{116}$. Autour de la même année, le Breviloquium affirme qu'un descendant de Frédéric II conquerra, comme jadis le roi de Perse, la Grèce et tous les royaumes de la terre : il rebâtira, avec un nouveau Zorobabel, le temple de Jérusalem et les murs de la cité sainte, instaurant la paix dans son empire ${ }^{117}$. Francesc Eiximenis parle d'un antéchrist mixte issu de la maison d'Aragon qui remporte d'innombrables batailles navales, fait le passage en Terre sainte et est adoré par tous les rois de la terre ${ }^{118}$. La bête de l'Apocalypse réalise, sous les traits du roi d'Aragon, une bien prestigieuse mission : elle efface l'Islam de la surface de la terre, prend Jérusalem et instaure la monarchie universelle.

En 1453, au lendemain de la chute de Constantinople, Alphonse V, conquérant de Naples, avait été pressenti par la papauté comme le meneur d'une croisade anti-turque. Il était alors chanté, en Catalogne, comme la chauve-souris qui étendrait sa puissance en Orient. Ces thèmes se retrouvent

113. A. Milhol, "La chauve-souris... », art. cité, et Colón y su mentalidad mesiánica en el ambiente franciscanista español, Valladolid, 1983.

114. JacQues I', Crònica, F. Soldevila éd., Barcelone, 1971, p. 144, \$389.

115. P. Bohigas, «Profecies de Merlí... », art. cité, p. 271.

116. M. Aurrell, "Prophétie et messianisme... », art. cité, pp. 336-337 et 353.

117. H. Lee, M. E. Rfives, G. Silano, Western..., op. cit., p. 249.

118. A. G. HalF, "El De triplici... », art. cité, pp. 275-276 et n. 45. 


\section{RITES, MÉMOIRE ET PROPHÉTIES}

dans le poème qu'Ausias March (1397-1459), fauconnier du roi, engagé auprès de lui dans la campagne de Bonifacio, avait composé quelques années auparavant : "Le grand cor de cet homme vaillant sonne si fort qu'il assourdit les Indiens ; les peuples qui sont du côté de la Tramontane, du couchant et du levant l'entendent »; "Toutes les terres du monde, les royaumes grands et petits, seront donnés, en bref, à cet homme justifié qui en aura la monarchie »119. La conquête de l'Orient, jusqu'aux Indes, mène à l'empire universel.

Les historiens modernistes ont insisté sur l'influence de ces idées dans la perception de l'image et de la mission de Ferdinand le Catholique ${ }^{120}$ : lors de ses entrées à Barcelone, les conseilleurs le saluent comme la chauvesouris attendue par ses royaumes, comme le nouveau David, comme le soleil éclairant la terre, voire comme le Messie lui-même. Ces expressions hyperboliques atteignent leur paroxysme avec la conquête de Grenade, achèvement heureux de la Reconquista, accompli par Ferdinand, réincarnation de Ferdinand III le Saint, conquérant de Séville et de Cordoue. L'événement admirable en 1492 est perçu par la propagande Trastamare comme le prodrome de la domination sur la Berbérie, phase préalable à la prise de Jérusalem ${ }^{121}$. Christophe Colomb, auteur d'un livre de prophéties, où il cite explicitement les oracles de Joachim sur la reconstruction de Sion par un roi d'Aragon ${ }^{122}$, persuade même les Rois Catholiques de subventionner, cette même année, son expédition en leur faisant miroiter la possibilité d'atteindre, par une route occidentale, la Ville sainte qui leur est promise de toute éternité ${ }^{123}$. De Jérusalem à l'Amérique, la diffusion des vaticinations relatives au messianisme de la royauté aragonaise a beaucoup contribué à la découverte du Nouveau Monde ${ }^{124}$.

Tout au long des $14^{\mathrm{e}}$ et $15^{\mathrm{e}}$ siècles, un discours utopique est diffusé par la propagande du roi d'Aragon. Dragon ailé effrayant ses adversaires, chauve-souris dévorant les musulmans, aigle châtiant les mauvais clercs, bâton réformant les mœurs ecclésiastiques, nouveau David rebâtissant le Temple, lion rugissant jusqu'à Sion, le monarque se trouve au centre d'un combat apocalyptique. "Anté-Christ » plutôt qu' "Anti-Christ », ange exterminateur exécutant les punitions prévues par la Providence, Empereur

119. P. Bohicias éd., Barcelone, 1954, t. III, p. 97.

120. Cf. E. Duran, Simbologia política..., op. cit.

121. Ya les dixe ay profecia / de antiguos libros sacada / que Fernando se diría / aquel que conquistaría / Jherusalen y Granada. Pedro Marcuel lo, Cancionero, J. M. Bi.ecla éd., Saragosse, 1987, p. 29. Le notable aragonais Pedro Marcuello ( $† 1502)$, qui compose son chansonnier à la gloire des rois catholiques, était neveu du chambrier de Ferdinand II.

122. El abad Johachín, calabrés, diso que había de salir de España quien havía de redificar la casa del monte Sion. C. de Lol.t.s éd., Raccolta di documenti e studi pubblicati dalla reale commissione colombiana, Rome, 1894, p. 83.

123. M. MAHn-Lor, Portrait historique de Christophe Colomb, Paris, 1988 ; B. VInCENT, 1492, l'année admirable, Paris, 1991, pp. 66-67.

124. A. Mir.Hot, Colón y su mentalidal..., op. cit. 
des derniers temps préparant la Parousie, il est voué à la monarchie universelle, à la domination de la terre tout entière. Il instaurera bientôt le millenium, une période heureuse de paix et de prospérité se substituant au monde ancien et décadent aboli à jamais. Cette abondance de métaphores vise à exalter la toute-puissance d'un roi dont le pouvoir n'a cessé de grandir depuis le $12^{\mathrm{e}}$ siècle.

Au fil des années, son impérialisme le rend maître de la Méditerranée occidentale. Les efforts de la papauté et de la maison de France pour arrêter son expansion sont vains : ils le jettent dans une dissidence institutionnalisée, d'autant plus justifiable qu'elle est voulue par la divinité qui fait du monarque son agent eschatologique. Les marchands catalans et majorquins appuient ce programme thalassocratique : le joachimisme des franciscains spirituels qu'ils fréquentent donne un rassurant aval à cette aventure incertaine. L'hétérodoxie de leurs prises de position sur la pauvreté et la persécution qu'elle entraîne scellent leur alliance avec une dynastie qui, descendant de Frédéric II, n'est autre que celle des Hohenstaufen excommuniés.

La croissance quantitative de la puissance aragonaise par l'annexion de principautés s'accompagne d'une augmentation qualitative de la nature du pouvoir régalien. Rien n'étanche la soif de domination du roi et de son entourage, rétifs à tout contre-pouvoir. Le monarque, jadis respectueux d'un ordre préétabli, s'engageant par serment à veiller sur les privilèges de ses sujets, est devenu la source première, unique et suprême de la loi. Prophète et astrologue, il dispose désormais d'un savoir ésotérique lui permettant de gouverner sans partage en pleine connaissance de cause. Supérieur, il annule les libertés ecclésiastiques, municipales et nobiliaires, à l'image de Pierre IV déchirant, de ses propres mains, dans un accès de colère, les chartes des privilèges jadis octroyés aux nobles en révolte. Les guerres civiles qui s'ensuivent empêchent, cependant, à la confédération catalano-aragonaise de sombrer dans l'absolutisme. La propagande royale n'entend pas moins abandonner la partie et diffuse abondamment des thèmes messianiques.

L'impérialisme méditerranéen, l'intégration territoriale de principautés lointaines et la lutte contre les corps intermédiaires de gouvernement entraînent ainsi d'âpres combats. Les figures évoquant la destruction militaire et la dévastation par les armes abondent dans nos oracles : feu et fumée, liés au nom du roi Alphonse, creuset fondant le métal mixte, dont dérive le nom de Ferdinand, autel de la bataille, étymologie de l'Aragon, Mars, devenu l'astre belliqueux de Pierre IV, sang montant jusqu'aux croupes des chevaux des soldats de Salses... autant d'allégories renvoyant aux horreurs de la guerre, omniprésente en Catalogne. Autour de la figure d'un roi déifié, une conscience nationale est en train de naître : les symboles identitaires qu'elle emprunte sont trop souvent négatifs, hostiles au clergé, aux Angevins et à l'Islam. Ils témoignent de toute la violence de la genèse de l'État moderne, dévorateur des solidarités anciennes et des libertés séculaires.

Martin AURELL Université de Poitiers 